Boise State University

ScholarWorks

Mathematics Faculty Publications and

Presentations

$2-2016$

Evaluation of NASA's MERRA Precipitation Product in Reproducing the Observed Trend and Distribution of Extreme Precipitation Events in the United States

\author{
Hamed Ashouri \\ University of California, Irvine \\ Soroosh Sorooshian \\ University of California, Irvine \\ Kuo-Lin Hsu \\ University of California, Irvine \\ Michael G. Bosilovich \\ NASA Goddard Space Flight Center \\ Jaechoul Lee \\ Boise State University
}

See next page for additional authors

This document was originally published in Journal of Hydrometeorology by the American Meteorological Society.

Copyright restrictions may apply. doi: 10.1175/JHM-D-15-0097.1 


\section{Authors}

Hamed Ashouri, Soroosh Sorooshian, Kuo-Lin Hsu, Michael G. Bosilovich, Jaechoul Lee, Michael F. Wehner, and Allison Collow 


\title{
Evaluation of NASA's MERRA Precipitation Product in Reproducing the Observed Trend and Distribution of Extreme Precipitation Events in the United States
}

\author{
Hamed Ashouri, Soroosh Sorooshian, AND KuO-Lin Hsu \\ Center for Hydrometeorology and Remote Sensing, Department of Civil and Environmental Engineering, \\ University of California, Irvine, Irvine, California \\ MichaEl G. BOSILOVICH \\ Modeling and Assimilation Office, NASA Goddard Space Flight Center, Greenbelt, Maryland
}

JAECHOUL LEE

Department of Mathematics, Boise State University, Boise, Idaho

MiCHAEL F. WEHNER

Lawrence Berkeley National Laboratory, Berkeley, California

ALlisOn COLLOW

Universities Space Research Association, Columbia, and Modeling and Assimilation Office, NASA Goddard Space Flight Center, Greenbelt, Maryland

(Manuscript received 13 June 2015, in final form 27 October 2015)

\begin{abstract}
This study evaluates the performance of NASA's Modern-Era Retrospective Analysis for Research and Applications (MERRA) precipitation product in reproducing the trend and distribution of extreme precipitation events. Utilizing the extreme value theory, time-invariant and time-variant extreme value distributions are developed to model the trends and changes in the patterns of extreme precipitation events over the contiguous United States during 1979-2010. The Climate Prediction Center (CPC) U.S. Unified gridded observation data are used as the observational dataset. The CPC analysis shows that the eastern and western parts of the United States are experiencing positive and negative trends in annual maxima, respectively. The continental-scale patterns of change found in MERRA seem to reasonably mirror the observed patterns of change found in CPC. This is not previously expected, given the difficulty in constraining precipitation in reanalysis products. MERRA tends to overestimate the frequency at which the 99th percentile of precipitation is exceeded because this threshold tends to be lower in MERRA, making it easier to be exceeded. This feature is dominant during the summer months. MERRA tends to reproduce spatial patterns of the scale and location parameters of the generalized extreme value and generalized Pareto distributions. However, MERRA underestimates these parameters, particularly over the Gulf Coast states, leading to lower magnitudes in extreme precipitation events. Two issues in MERRA are identified: 1) MERRA shows a spurious negative trend in Nebraska and Kansas, which is most likely related to the changes in the satellite observing system over time that has apparently affected the water cycle in the central United States, and 2) the patterns of positive trend over the Gulf Coast states and along the East Coast seem to be correlated with the tropical cyclones in these regions. The analysis of the trends in the seasonal precipitation extremes indicates that the hurricane and winter seasons are contributing the most to these trend patterns in the southeastern United States. In addition, the increasing annual trend simulated by MERRA in the Gulf Coast region is due to an incorrect trend in winter precipitation extremes.
\end{abstract}

Corresponding author address: Hamed Ashouri, Center for Hydrometeorology and Remote Sensing, Department of Civil and Environmental Engineering, University of California, Irvine, Irvine, CA 92697.

E-mail: h.ashouri@uci.edu 


\section{Introduction}

Reanalysis (or retrospective analysis) is a method that assimilates observational data into a model forecast to update the status of the system to eventually produce a comprehensive record of atmospheric and oceanic variables (Smith et al. 2014). Reanalysis products help the scientific and user communities investigate how Earth's weather and climate systems are changing over the course of time. Reanalyses usually provide more than three decades of data globally. Such characteristics make them well suited for long-term climate studies, particularly in the warming climate (IPCC 2013). In particular, reanalysis products can be used to study the impacts of climate change on the extreme phases of our climate system (e.g., floods, droughts, hurricanes, heat waves, and cold snaps). These events claim lives all around the world and cause billions of dollars in economic damage and human hardship (NCDC 2012; Smith and Katz 2013). Examples of these events are the 2013 flood in Colorado, the 2013 Supertyphoon Haiyan in the Philippines, and the 2010 Pakistani flood and Russian heat wave, among many other events worldwide.

To date, many studies with regard to climate extremes have been carried out (e.g., Karl et al. 1993; Easterling et al. 2000; Higgins et al. 2000; Groisman et al. 2005, 2012; Wehner 2005; Alexander et al. 2006; Kharin et al. 2007; Brown et al. 2008; Karl et al. 2009; DeGaetano 2009; Kunkel et al. 2010; Karl et al. 2012; Peterson et al. 2013, 2014; Dulière et al. 2013; Westra et al. 2013; Kharin et al. 2013; Kunkel et al. 2013; Gervais et al. 2014; Wuebbles et al. 2014a,b). However, not as much attention has been paid to the application of the reanalyses in studying weather and climate extremes (Schenkel and Hart 2012). Zolina et al. (2004) compared the statistical characteristics of daily precipitation in the National Centers for Environmental Prediction (NCEP) and the European Centre for Medium-Range Weather Forecasts (ECMWF) reanalysis products over Europe. The study reported that NCEP-2 outperformed NCEP-1 and the ECMWF reanalyses (ERA-15 and ERA-40), showing the closest performance to rain gauge data. In the meantime, many studies using reanalyses either consider long-term climate means or individual weather events (e.g., Bosilovich et al. 2008; Ma et al. 2009; Trenberth et al. 2011; Rana et al. 2015). This evaluation study of weather extremes considers the weather-scale occurrences of extreme precipitation events over a long period, which will aid in the understanding of the ability of reanalyses to reproduce weather events. Our focus is on NASA's Modern-Era Retrospective Analysis for Research and Applications (MERRA) precipitation product (Rienecker et al. 2011; Lucchesi 2012) and how well this product captures the behavior of historical extreme precipitation events. MERRA has been used in different studies (e.g., Bosilovich et al. 2011; Trenberth et al. 2011; Bosilovich 2013). This product has been shown to reproduce relevant large-scale dynamics involved in the formation of regional climate extremes (Schubert et al. 2011; Wang et al. 2014). However, because precipitation in reanalyses is related to the physical parameterizations in the modeling system, we investigate the precipitation focused on extreme analyses.

In this study, we seek to evaluate how well MERRA would reproduce the probability distribution of historical extreme precipitation events. For this purpose, we deploy methods from statistics that specifically deal with rare weather events. Extreme value theory (EVT) has recently emerged as one of the widely used methods in modeling climate extremes (Zhang et al. 2001; Katz et al. 2002; Cooley 2009; Cooley and Sain 2010; Kharin et al. 2007; Katz 2010; Towler et al. 2010; Villarini et al. 2011; Katz 2013). Wehner (2013) used the EVT distributions to analyze 20-yr return values of seasonal extreme daily precipitation in the ensemble of the North American Regional Climate Change Assessment Program (NARCCAP) regional climate models and found that performance of regional models of approximately $50 \mathrm{~km}$ in horizontal resolution varied widely in their ability to reproduce observed precipitation extremes. In another study, Lee et al. (2014) developed statistical models from the EVT to estimate trends in monthly extreme temperature events in the 48 contiguous United States (CONUS). The results showed that, while monthly maximum temperatures are not significantly changing, monthly minimum temperatures depict a significant warming trend.

In this study, we examine both the annual maximum precipitation events and the precipitation peaks above a certain threshold. We will first conduct a trend analysis on the annual maxima and investigate how well MERRA can capture those trends when compared to observational data. Then using EVT generalized extreme value (GEV) statistical methods, each extreme category is modeled with a specific type of GEV distribution, and the accuracy of MERRA in capturing those distributions is assessed. To account for the nonstationarity effects of climate change and global warming (IPCC 2013) and possible changes in the probability distribution of extremes, we will let one of the parameters of the GEV distribution (in the case of annual maxima) be able to change over time. A statistically significant trend, if any, in this parameter is an identification of a statistically significant trend in the distribution of the extremes. This is implemented for both MERRA and the observational data products to 
evaluate the performance of MERRA. The study is conducted over the CONUS for 1979-2010, and the Climate Prediction Center (CPC) U.S. Unified precipitation data are used as the observational dataset.

The paper is organized as follows: in section 2, we present a brief description of the data that are used; in section 3, the two EVT approaches selected for modeling the precipitation extremes in this study are explained in detail; the results are presented in section 4; in section 5 , we discuss some of the features identified in the results section; and finally, in section 6 , we provide a summary of the key findings of this research.

\section{Data}

\section{a. The CPC U.S. Unified precipitation product}

The National Oceanic and Atmospheric Administration's (NOAA) CPC U.S. Unified precipitation product is part of the CPC Unified global precipitation project. CPC uses its data sources and interpolation objective analysis techniques to create consistent and high-quality global precipitation products. Chen et al. (2008a) used three objective techniques, including two inverse-distanceweighting algorithms, and the optimal interpolation (OI) method to obtain the CPC gauge-based daily precipitation analyses. The study shows that all three methods are capable of generating useful daily precipitation analyses with biases of generally less than $1 \%$. The results also show that the OI method consistently performs the best among the three techniques for almost all situations.

The CPC U.S. Unified gauge-based analysis product that is used in this study covers the CONUS on a daily scale at a $0.25^{\circ} \times 0.25^{\circ}$ spatial resolution and is quantitatively consistent with that covering the global land on a coarser resolution (i.e., $0.5^{\circ}$ ). Three data sources, including 1) NOAA's National Climatic Data Center (NCDC), 2) River Forecast Centers (RFCs), and 3) daily accumulation from hourly precipitation data, are used in generating the CPC precipitation. Further detailed information regarding the interpolation algorithm and evaluation processes for generating the CPC product are described in Xie et al. (2007), Xie et al. (2010), and Chen et al. (2008a,b). In this study, the CPC gridded data are considered as the reference gaugebased dataset for comparing the performance of MERRA in modeling extreme precipitation events. The quality of the gridded CPC product depends on the density of stations' network; however, as noted in Chen et al. (2008a), the OI technique that is used to generate CPC U.S. Unified precipitation product shows stable performance statistics even over regions with sparse gauges. The CPC gridded dataset does not have any missing data.

\section{b. The MERRA precipitation product}

NASA's MERRA product is designed to support NASA's Earth science research interests by producing a global long-term dataset for the satellite era from 1979 to present (Rienecker et al. 2011). Scientists at the Global Modeling and Assimilation Office (GMAO) at the Goddard Space Flight Center (GSFC) use the Goddard Earth Observing System Model, version 5 (GEOS-5), and data assimilation techniques to generate the MERRA product at a spatial resolution of $1 / 2^{\circ}$ latitude $\times 2 / 3^{\circ}$ longitude with 72 model vertical levels (Rienecker et al. 2008; Lucchesi 2012). By using an incremental analysis update that minimizes the spindown effects of the water vapor analysis, and also by providing an extensive number of variables at a relatively high spatial resolution, MERRA has shown improvements in representing large-scale global precipitation, particularly in the tropical regions (Bosilovich et al. 2011; Bloom et al. 1996). However, continental-scale precipitation remains a challenge for all global reanalyses, including MERRA, when compared to the Global Precipitation Climatology Project (GPCP). Bosilovich (2013) analyzed summer seasonal precipitation in recent reanalyses to show that MERRA was not able to produce highs and lows in the summer seasonal time series, especially in the midwestern United States.

\section{Methodology}

Practical explanations and documentations about EVT are presented in Coles (2001) and Castillo et al. (2005). Our extreme daily precipitation study uses the two most well-adopted extreme value analysis approaches. In the first approach, known as the block maxima approach, the maximum daily precipitation of each year during 1979-2010 in the CPC and MERRA is used to generate an extreme sample of the parent distribution of all precipitation events. In the second approach, known as the peaks over threshold (POT) method, a certain threshold is set, and all of the rainfall values greater than or equal to that threshold are used to generate the extreme sample. Details of fitting distributions to these extreme samples are discussed below. MATLAB (MathWorks 2011) and R (R Core Team 2013) environments are used for computer coding and building the statistical models.

\section{a. Block maxima approach}

In this method, a "block" is defined as 1 year, and the maximum daily precipitation in each year is considered as 
the block maxima. This variable is hereafter called annual maximum daily precipitation (AMDP). For each $0.5^{\circ}$ pixel of the CONUS, we assume that the sequence (indicated by curly brackets) of AMDP $\left\{X_{t}\right\}$, extracted from each of the CPC and MERRA datasets, is independent in time. Because the block size (365, or 366 days in the case of leap years) is large enough, according to the FisherTippett theorem (Fisher and Tippett 1928), the marginal cumulative distribution function for AMDP $\{X\}$ can be well approximated by the GEV distribution:

$$
G(x ; \mu, \sigma, \xi)=P(X \leq x)=\exp \left\{-\left[1+\xi\left(\frac{x-\mu}{\sigma}\right)\right]^{-1 / \xi}\right\}
$$

for $x$ with $1+\xi[(x-\mu) / \sigma]>0$, where $G(\cdot)$ is the cumulative distribution function for the GEV distribution at an arbitrary value $x, P$ denotes the probability, $\Gamma$ is the gamma function, and $\mu, \sigma$, and $\xi$ are unknown location, scale, and shape parameters of $G(\cdot)$, respectively. If $\xi<1$, the mean (expected) value of $X$ is

$$
E(X)=\mu+\frac{\sigma}{\xi}[\Gamma(1-\xi)-1] .
$$

To examine possible changes in the distribution of the AMDP events over time, we may further parameterize the location parameter in Eqs. (1) and (2) as a linearly time-variant parameter inside the GEV distribution function, relaxing the requirement that the PDF be stationary in time:

$$
\mu_{t}=\beta_{0}+\beta_{1} t
$$

where $\beta_{0}$ and $\beta_{1}$ are the unknown location and slope parameters, respectively. We interpret $\beta_{1}$ as the linear trend in extreme precipitation as the expected change in $X_{t}$ from time $t$ to $t+1$ is

$$
E\left(X_{t+1}\right)-E\left(X_{t}\right)=\mu_{t+1}-\mu_{t}=\beta_{1} .
$$

The maximum likelihood (ML) method is used to find the estimates of the unknown parameters in the GEV distribution function. For this, we numerically find the values of the parameters that maximize the GEV likelihood function:

$$
L\left(\beta_{0}, \beta_{1}, \sigma, \xi ; x_{1}, \ldots, x_{n}\right)=\prod_{t} f\left(x_{t} ; \beta_{0}, \beta_{1}, \sigma, \xi\right),
$$

where $f\left(x ; \beta_{0}, \beta_{1}, \sigma, \xi\right)=(d / d x) G\left(x ; \beta_{0}, \beta_{1}, \sigma, \xi\right)$ is the probability density function of the GEV distribution. The standard errors for the ML estimates are obtained from the information matrix of the likelihood fit. These standard errors will be used for significance tests for the estimated linear trends in the AMDP events. These methods are applied to each pixel of the CONUS for the CPC and MERRA datasets. In this study, we consider both time-invariant and time-variant GEV models.

\section{b. POT approach}

A caveat pertinent to the first approach is the possibility of wasting useful data, because the GEV distribution only considers the maximum precipitation of each year (Coles 2001; Zolina et al. 2013). To overcome this drawback, we first define significant daily precipitation as those rainfall data being at least $1 \mathrm{~mm}$ day $^{-1}$ and then use the top $1 \%$ heavy (99th percentile) rainfall of these significant precipitation data at each pixel as the threshold for our POT method. We then consider only the precipitation amounts that are greater than the 99th percentile threshold in our POT extreme precipitation modeling procedure. This variable is called annual extreme daily precipitation (AEDP). We also applied a declustered scheme to the AEDP variables by clustering the peaks that belong to the same cluster and only choosing the maximum peak as the representative of the cluster, so that the Poisson assumption is better maintained (Coles 2001). In POT, the generalized Pareto (GP) distribution is considered as an appropriate limiting probability distribution to model these threshold declustered exceedances. We assume that the precipitation exceedance $Y=X-u$ conditioned on that $X>u$ has the following GP distribution:

$$
H(y ; \tilde{\sigma}, \xi)=P(X \leq y+u \mid X>u)=1-\left(1+\frac{\xi y}{\tilde{\sigma}}\right)^{-1 / \xi}
$$

for $y>0$ and $1+\xi y / \tilde{\sigma}>0$, where $H(y)$ is the cumulative distribution function for the GP distribution at an arbitrary value $y, \tilde{\sigma}$ is the scale parameter for the GP distribution, and $u$ is the threshold. It is noteworthy that $\tilde{\sigma}=\sigma+\xi(u-\mu)$. Like the GEV method, maximizing the likelihood function

$$
L\left(\tilde{\sigma}, \xi ; y_{1}, \ldots, y_{n}\right)=\prod_{t} \frac{d}{d y_{t}} H\left(y_{t} ; \tilde{\sigma}, \xi\right)
$$

produces the ML estimates for $\tilde{\sigma}$ and $\xi$. We fit this GP model to every pixel of the CONUS for the CPC and MERRA datasets. In this study, we only consider timeinvariant GP models.

\section{Results}

\section{a. Annual maximum daily precipitation}

\section{1) TIME-INVARIANT CONDITION}

Before addressing the extreme value distributions, the climatology of AMDP, number of wet days, and 

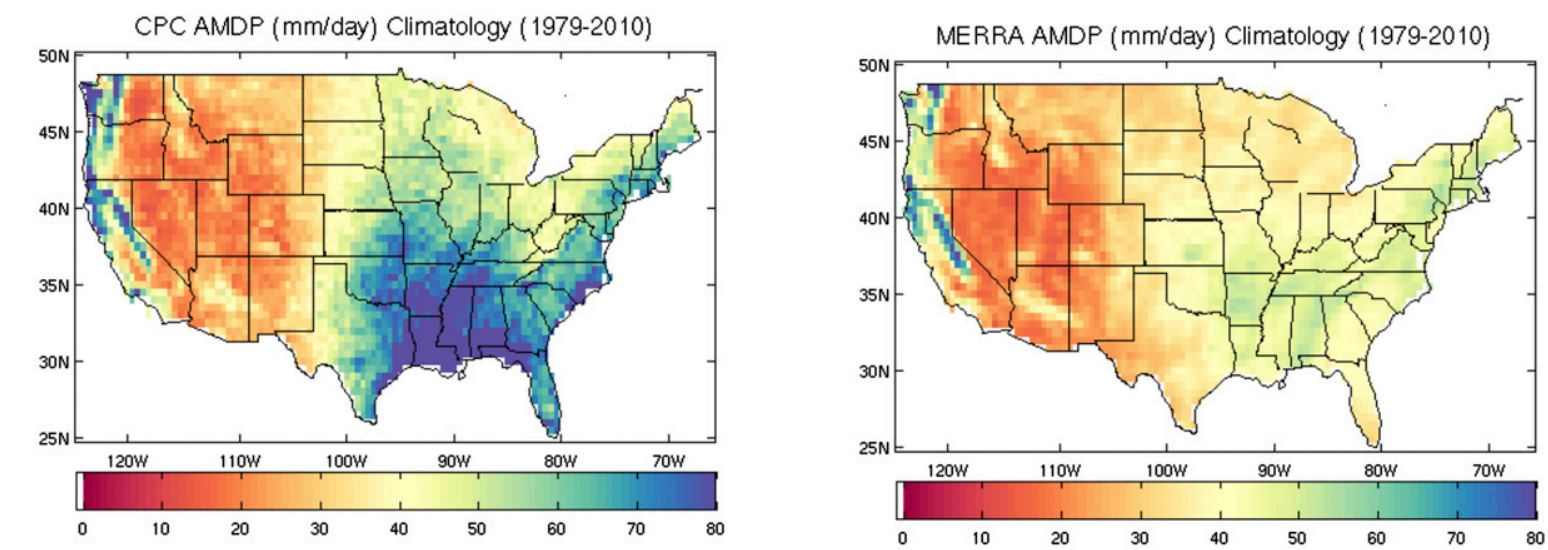

CPC ANN Average \# Wet Days Exceeding the $99^{\text {th }}$ Pctl of Precipitation

MERRA ANN Average \# Wet Days Exceeding the $99^{\text {th }}$ Pctl of Precipitation
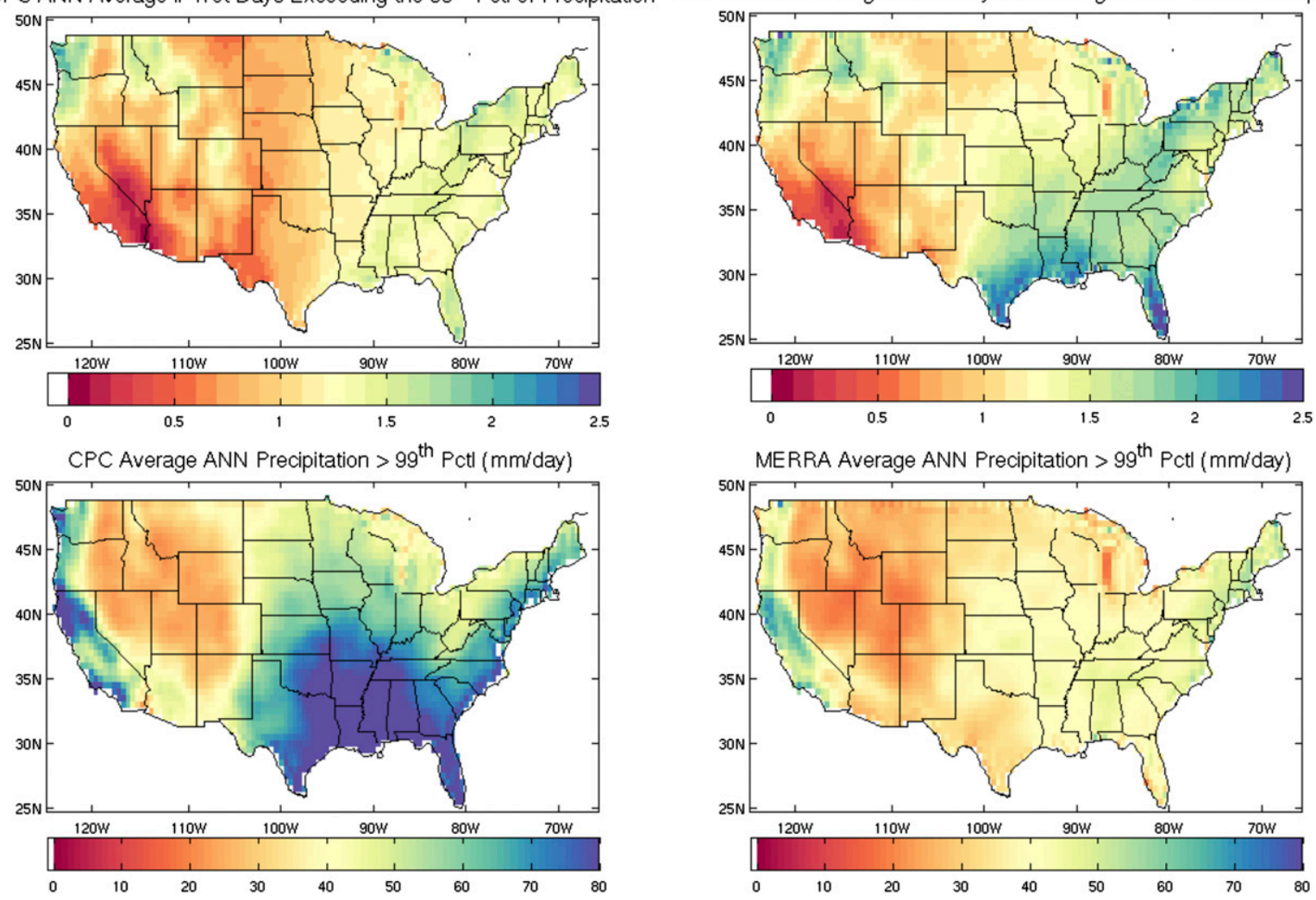

FIG. 1. (top) Long-term climatology of AMDP, (middle) average number of days when precipitation exceeded the 99th percentile, and (bottom) average precipitation intensities exceeding the 99th percentile.

intensity (scaled to the number of wet days) of precipitation extremes over the study period must be evaluated. This analysis was done at seasonal and annual time scales and selected results for the annual and JuneAugust (JJA) climatology and extremes can be seen in Figs. 1 and 2. Similar continental-scale patterns in the AMDP are seen in the CPC observations and MERRA, but MERRA underestimates the magnitude of the maximum precipitation, especially in JJA. This underestimation of the maximum precipitation primarily occurs to the east of the Rocky Mountains and is particularly evident over the Gulf Coast region. In addition to the mean and maximum daily precipitation, the average number of wet days that exceed the 99th percentile [Fig. 1 (middle) and Fig. 2 (middle)] and the average precipitation intensities exceeding the 99th percentile [Fig. 1 (bottom) and Fig. 2 (bottom)] were also examined. MERRA tends to overestimate the frequency at which the 99th percentile is exceeded in connection with the underestimation in the maximum daily 


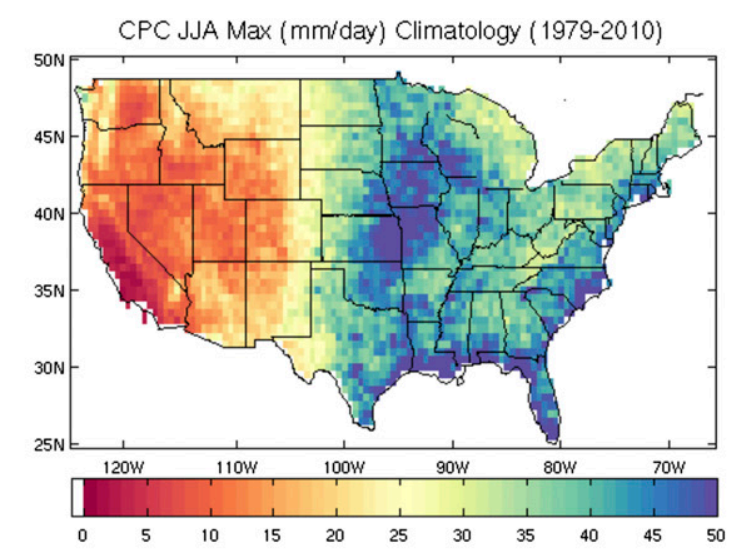

CPC JJA Average \# Wet Days Exceeding the $99^{\text {th }}$ Pctl of Precipitation
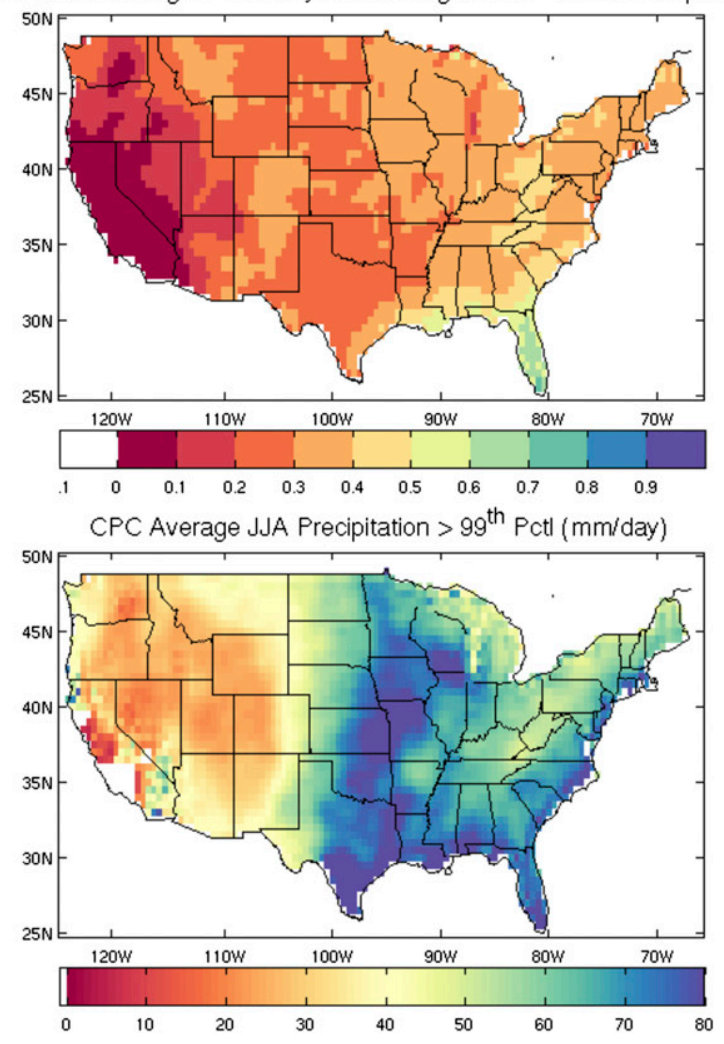

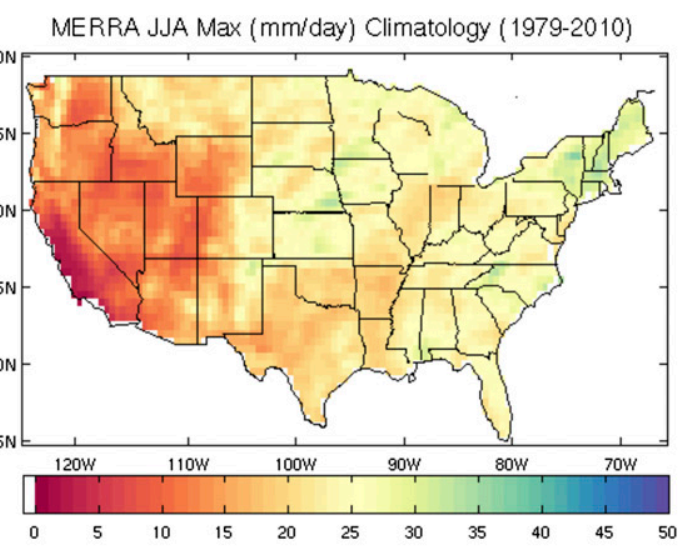

MERRA JJA Average \# Wet Days Exceeding the $99^{\text {th }}$ Pctl of Precipitation
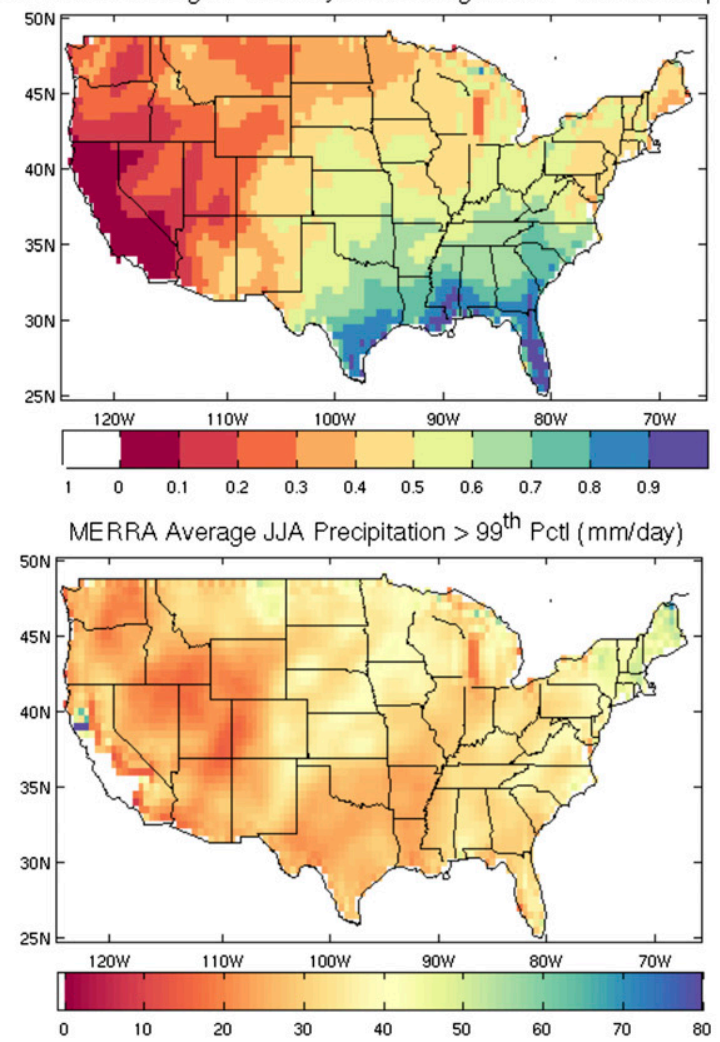

FIG. 2. (top) Long-term climatology of JJA max daily precipitation events, (middle) average number of days in JJA when precipitation exceeded the 99th percentile, and (bottom) average precipitation intensities in JJA exceeding the 99th percentile.

precipitation. The value representing the 99th percentile of precipitation is lower in MERRA compared to the observations and is apparent in the underestimation in the intensity of precipitation on days that exceeded the 99th percentile. As a result, there is a great likelihood that the precipitation on a given day will exceed the 99th percentile in MERRA compared to the observations. This feature is dominant during the summer months and is observed to a lesser extent in the transition months. The number of days that exceed the 99th percentile and the intensity of the precipitation on those days were very similar between the CPC observations and MERRA during the December-February (DJF) season. The seasonality in the differences between extreme precipitation events in MERRA and the observations hints at the difficulty in simulating precipitation, especially at the extremes and when it is convective in nature.

In addition to the above analysis, it is worth exploring potential linear trends in the AMDP time series. A linear trend model is fitted to each $0.5^{\circ} \times 0.5^{\circ}$ grid box, and 

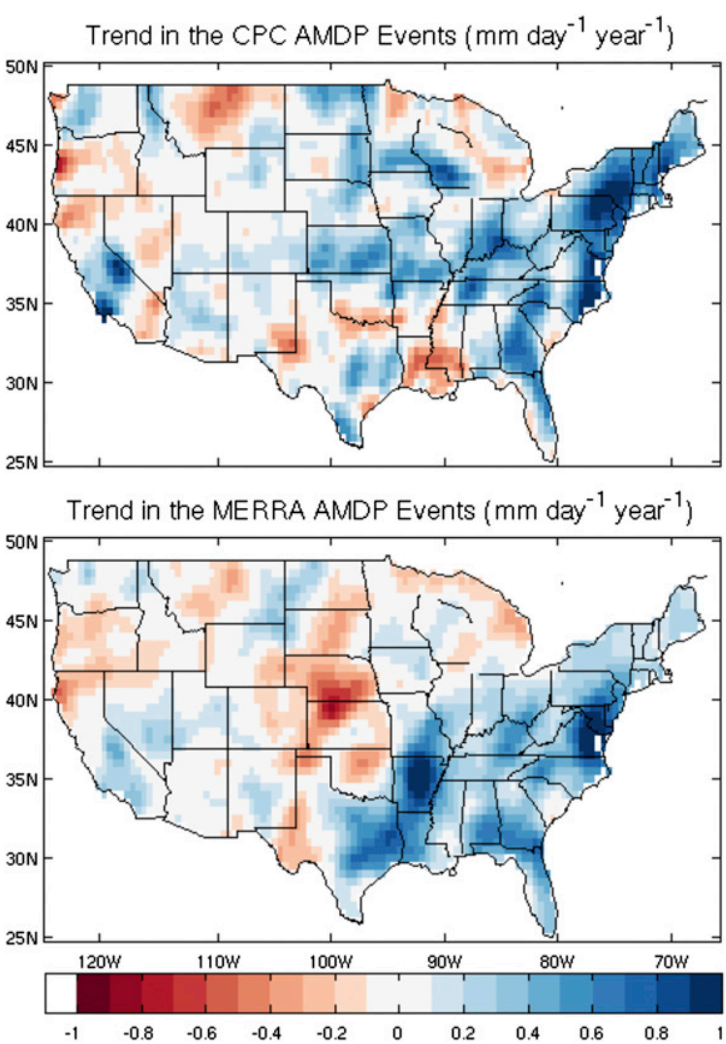

Significant trend $(95 \% \mathrm{Cl})$ in the CPC AMDP Events $\left(\mathrm{mm} \mathrm{day}^{-1}\right.$ year $\left.{ }^{-1}\right)$

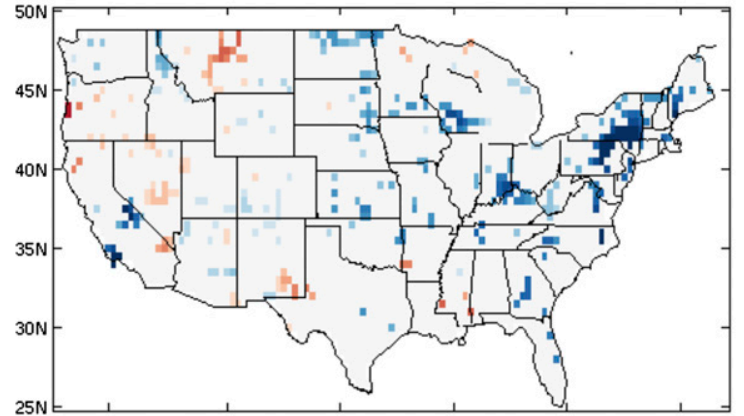

Significant trend $(95 \% \mathrm{Cl})$ in the MERRA AMDP Events $\left(\mathrm{mm}^{\text {day }}{ }^{-1}\right.$ year $\left.{ }^{-1}\right)$

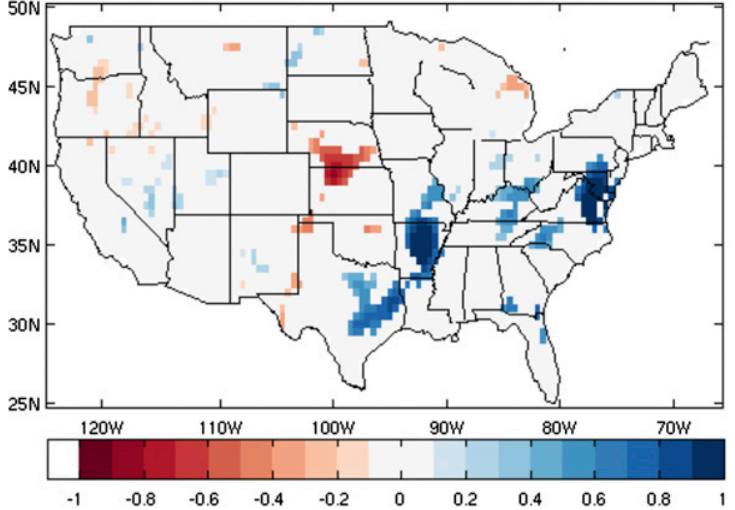

FIG. 3. (left) Trend ( $\mathrm{mm} \mathrm{day}^{-1} \mathrm{yr}^{-1}$ ) in AMDP from (top) CPC and (bottom) MERRA during 1979-2010. (right) The regions where the trend in AMDP is statistically significant at a 5\% significance level.

the resulting trend patterns, as well as the statistically significant ones, are identified. Figure 3 (left) shows the linear trend in the CPC (Fig. 3, top) and MERRA (Fig. 3, bottom) AMDP time series. In general, the pattern of changes identified in MERRA seems to reasonably mirror the observed pattern of changes in CPC. This is an interesting result, particularly in view of the difficulty in constraining precipitation in reanalysis products. The spurious negative trend in MERRA in the central United States over Kansas and Nebraskaopposite of the observed trend in the CPC-is certainly cause for questioning and will be discussed in section $5 \mathrm{a}$.

To identify the regions where the trends in AMDP events are statistically significant, a two-sided significance test was performed at the $5 \%$ significance level for every grid point. The results are shown in Fig. 3 (right). As shown, both CPC and MERRA exhibit an overall positive trend across the eastern United States, although some discrepancies exist location-wise. According to the CPC results, in the southwestern United States, AMDP shows significantly increasing trends in a few pixels, while MERRA underestimates the trend in this region.

As discussed in the previous section, AMDP sequences follow the GEV distribution. The time-invariant location, scale, and shape parameters of the GEV distribution [Eq. (1)] at each pixel for the two data products are estimated and displayed in Fig. 4. As shown, MERRA was able to reproduce similar spatial patterns for location and scale parameters, as observation data depict, while underestimating both parameters. Most of this underestimation happens to be in and around the Gulf Coast states and relatively over the East and West Coasts.

The scatterplots of the GEV parameters from MERRA AMDP compared against the respective parameters from the CPC AMDP as well as different statistics [correlation coefficient, root-mean-square error (RMSE), and bias] are also presented in Fig. 4. As shown, the underestimation of MERRA is clear. Furthermore, the relatively high correlation between the MERRA and CPC parameters ( 0.79 for the location parameter and 0.74 for the scale parameter) reaffirms the capability of MERRA to reproduce patterns similar to those of CPC. Spatial patterns of the shape parameter estimates are similar for MERRA and CPC. However, it is difficult to make a robust statement about the accuracy of the shape parameter estimates (Fig. 4, right) because the discrepancies between the $\xi$ patterns in the reanalysis and CPC are large and the correlation is very weak. 
GEV Location Parameter ( $\mu, \mathrm{mm} /$ day) for CPC AMDP

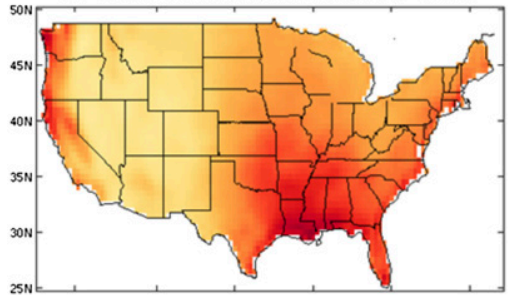

GEV Location Parameter ( $\mu, \mathrm{mm} /$ day) for MERRA AMDP

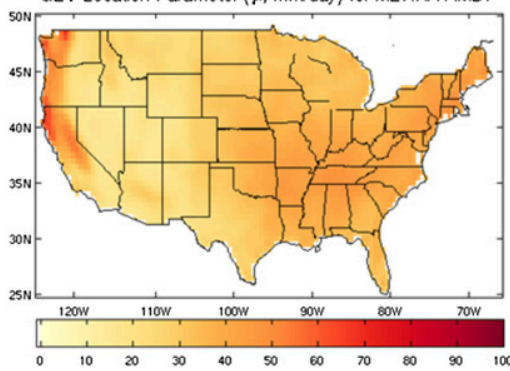

GEV Location Parameter ( $\mu$, mm/day)

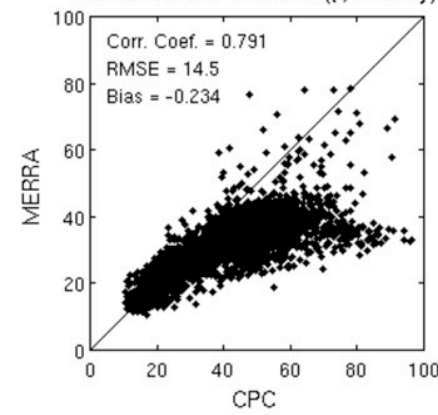

GEV Scale Parameter $(\sigma, \mathrm{mm} /$ day $)$ for CPC AMDP

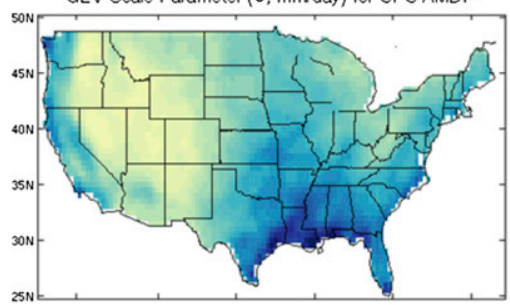

GEV Scale Parameter ( $\sigma, \mathrm{mm} /$ day) for MERRA AMDP
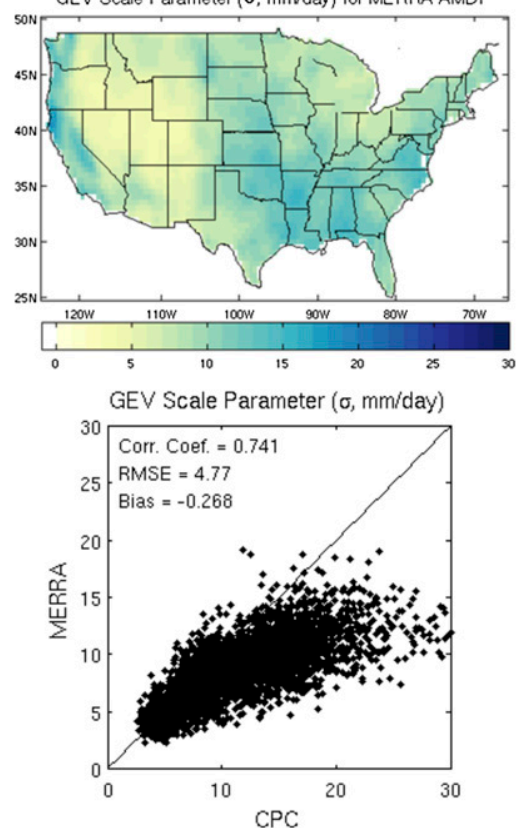

GEV Shape Parameter ( $)$ ) for CPC AMDP

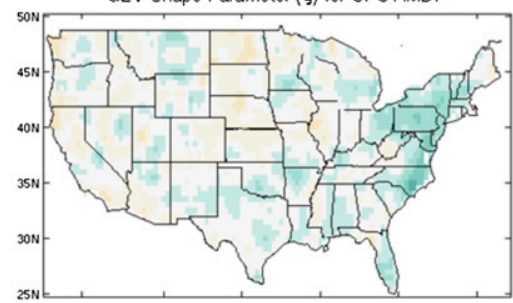

GEV Shape Parameter ( $(\xi)$ for MERRA AMDP

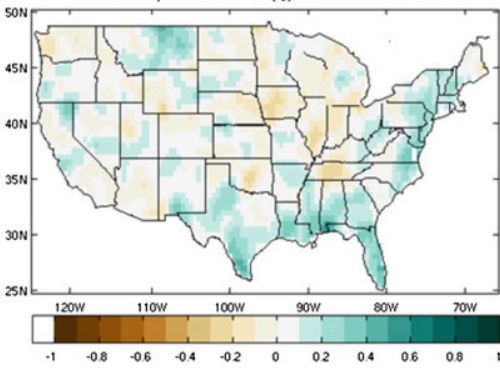

GEV Shape Parameter ( $\xi)$

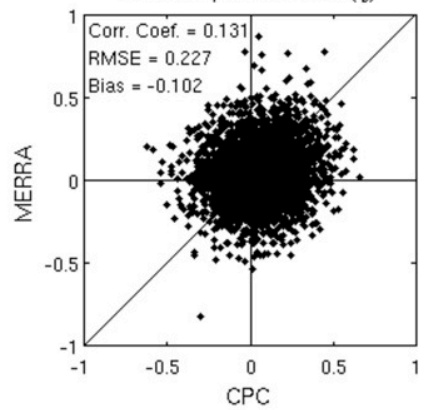

FIG. 4. (left) Location, (center) scale, and (right) shape parameters of the time-invariant GEV distributions of AMDP events from (top) CPC and (middle) MERRA during 1979-2010. (bottom) The respective scatterplots and quantitative statistics between the GEV parameters from the $\mathrm{CPC}$ and MERRA.

To test the GEV distribution goodness of fit, we used the Kolmogorov-Smirnov (KS) test (Massey 1951). For both of the rainfall products, the empirical and theoretical GEV cumulative distribution functions (CDF) at each pixel were built and considered for this purpose. We tested the null hypothesis to determine whether or not the AMDP data are from their theoretical GEV distribution. The KS test results showed that the null hypothesis was not rejected, thereby reaffirming that the GEV distribution is indeed the right fit for the AMDP data. We also examined the goodness-of-fit by $\mathrm{Q}-\mathrm{Q}$ plots of several randomly selected pixels. The Q-Q plots also verified that the GEV distribution is appropriate for the AMDP series.

\section{2) Time-VARIANT CONDITION}

So far, the parameters of the GEV distribution were considered constant and not changing over time; however, because of the impacts of climate change, the GEV distribution might have been changing over time. To investigate the possibility of the existence of such changes, we consider a time-variant GEV distribution model. Specifically, we assume that the GEV location parameter changes over time as modeled in Eq. (3), implying that the climate change induces a change in the precipitation mean. The time-variant GEV model given in Eq. (1), with $\mu$ parameterized as $\mu_{t}$ via Eq. (3), is fitted to each pixel in CPC and MERRA, and the four parameters $\beta_{0}, \beta_{1}, \sigma$, and $\xi$ are estimated.

To evaluate the statistical significance of the estimated GEV trends, we calculate and test the $z$ scores of the trend estimates. The $z$ score shows how many standard errors the estimated trend differs from zero. For a $5 \%$ significance test (two sided), a statistically significant trend is the one whose respective $z$ score is beyond the 2.5 th and 97.5 th percentile range $( \pm 1.96)$ of the standard normal distribution. Figure 5 displays the statistically significant trend (at the 5\% significance level) in the location parameter of the time-variant GEV distribution of AMDP events $\left(\beta_{1}\right)$. As shown, increasing trends in AMDP are more apparent in the eastern United 


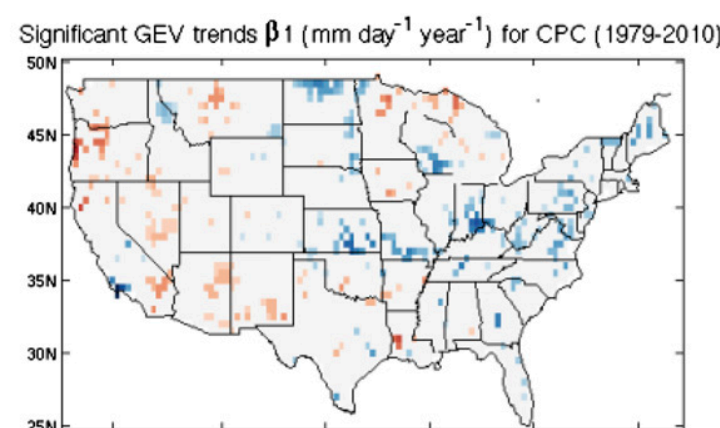

Significant GEV trends $\boldsymbol{\beta} 1$ ( $\mathrm{mm}$ day $^{-1}$ year $^{-1}$ ) for MERRA (1979-2010)

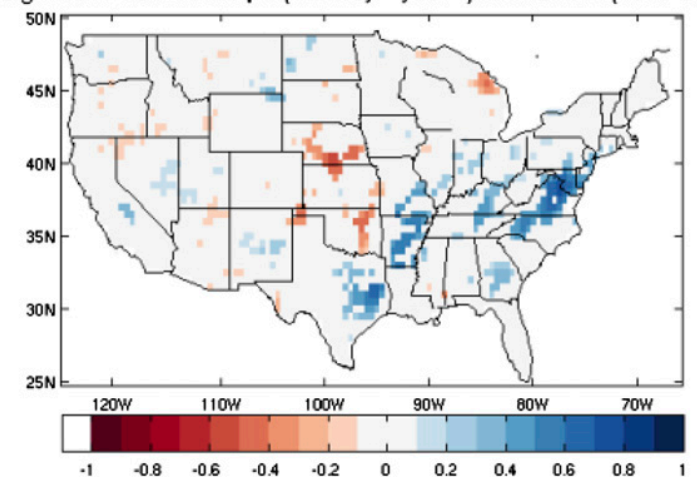

FIG. 5. Statistically significant trend $\left(\mathrm{mm} \mathrm{day}^{-1} \mathrm{yr}^{-1}\right)$ in the location parameter of the time-variant GEV distribution of AMDP events in (top) CPC and (bottom) MERRA at a 5\% significance level.

States than in the western United States. MERRA shows decreasing AMDP trends in the central United States. In addition, MERRA depicts more increasing trends for the southern United States, following a path from eastern Texas to Maryland.

The estimated scale parameters in the time-variant condition for both MERRA and CPC (Fig. 6) depict similar patterns as those observed and reported in the time-invariant condition. As can be seen in the spatial distribution maps of the scale parameter, MERRA reproduces the spatial patterns of the scale parameter of the time-variant GEV distribution reasonably well. However, MERRA again suffers from the underestimation of the magnitude of the scale parameter, particularly over the Sierra Nevada in the west, the Gulf Coast region, and along the East Coast up to the Northeast. The scatterplot and the statistics presented in Fig. 6 (bottom) show the same results.

Comparing the scatterplots and derived statistics from the CPC and MERRA estimated scale parameters in 1) time-invariant (Fig. 4, bottom) and 2) time-variant conditions (Fig. 6, bottom), we could see that while the RMSE and bias in the time-variant and time-invariant conditions are almost the same, the correlation coefficient in the time-variant condition is slightly higher than that of the time-invariant condition.
To better understand the difference of the GEV parameter estimates for CPC and MERRA as a whole, we compare the estimates of extreme quantiles in CPC and MERRA. Specifically, we calculate the return level for annual maximum precipitation using the time-variant GEV parameter estimates of CPC and MERRA (Coles 2001; Cooley 2013). Figure 7 shows the 25- (Fig. 7, top) and 50-yr (Fig. 7, bottom) return levels for CPC (Fig. 7, left) and MERRA (Fig. 7, right). The 25-yr return level is the amount of annual maximum precipitation that we expect to exceed once in the next 25 years. The $50-y r$ return (i.e., a 1-in-50 chance) level is interpreted in a similar manner. This figure shows that MERRA overall underestimates these return levels, noticeably in the East and the West Coast regions.

\section{b. Annual extreme daily precipitation}

Unlike the AMDP data, the linear trend in the declustered peaks above the 99th percentile (i.e., AEDP data) is not easily practicable because the temporal difference among these events is not a constant value over time. Instead, we looked at the number of AEDP events in each year and investigated potential statistically significant trends in the number of such events. As shown in Fig. 8 (left), the number of AEDP events increased for the eastern and northeastern United States, specifically for the states of Maine, New York, Pennsylvania, West Virginia, Indiana, and Georgia. Although MERRA shows an increasing trend in the eastern United States, location-wise discrepancies exist. The interesting point, however, is that, for both the AMDP and AEDP cases, the trend results are aligned with the results provided in the fourth National Climate Assessment (NCA) report for different regions over the United States. Based on the NCA report, "the Northeast has experienced a greater recent increase in extreme precipitation than any other region in the United States." Moreover, the report states that "the Northeast saw more than a $70 \%$ increase in the amount of precipitation falling in very heavy events (defined as the heaviest $1 \%$ of all daily events)" (Horton et al. 2014, p. 373).

As seen in the case of modeling the AMDP time series, MERRA depicts a spurious negative trend in Nebraska and Kansas. Potential reasons for this disagreement with the observations will be investigated in detail in section 5a. However, in addition to this, the increasing trends in the number of AEDP events over the Gulf Coast states (e.g., Texas and Louisiana) and farther inland (e.g., Arkansas), as well as along the East Coast (as is clear in Fig. 8), seem to be correlated with rainfall systems (mainly hurricanes and tropical cyclones) in this area of the CONUS. Going back to Figs. 3 and 5, similar patterns of increasing trends can 


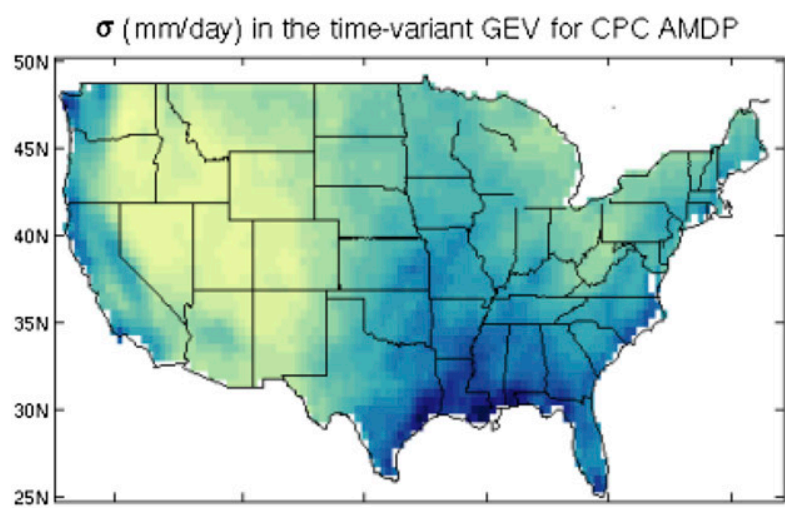

$\sigma$ (mm/day) in the time-variant GEV for MERRA AMDP
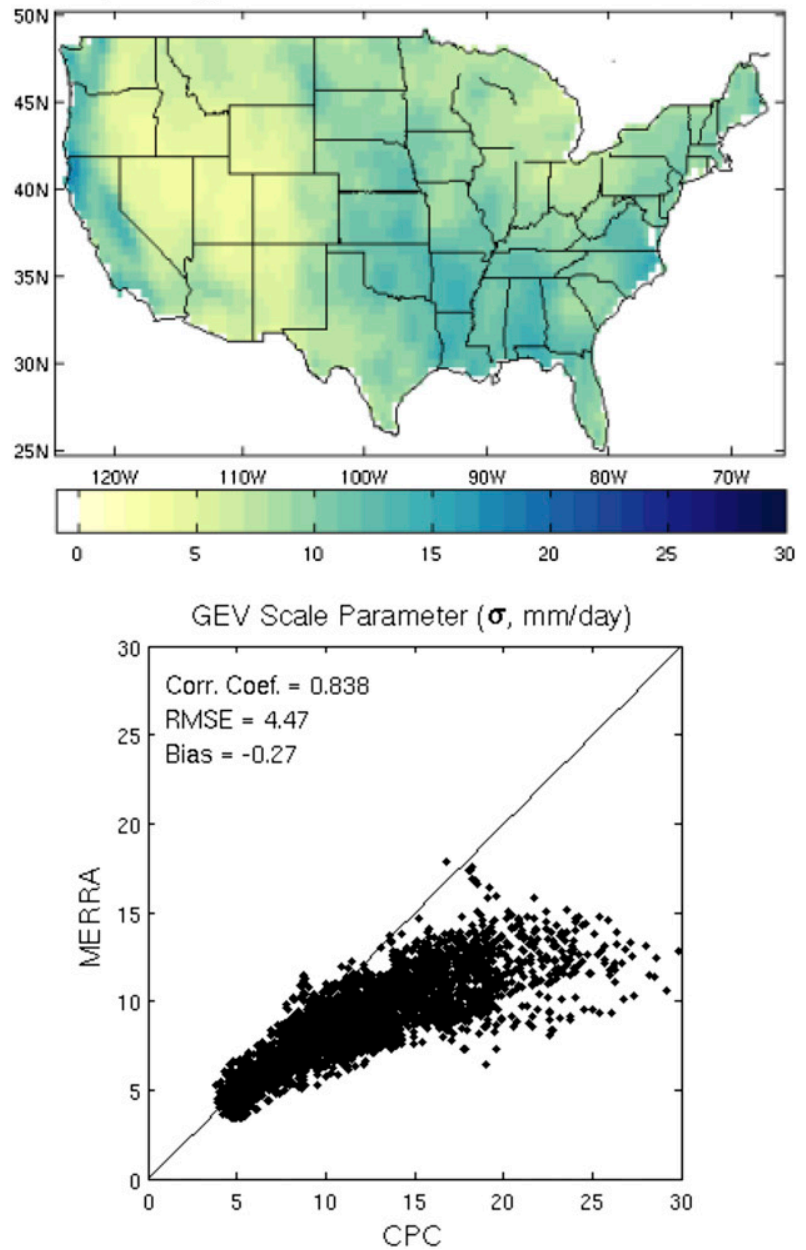

FIG. 6. Estimated scale parameter of the time-variant GEV distribution for (top) CPC and (middle) MERRA. (bottom) The respective scatterplot and quantitative statistics between the GEV scale parameter from CPC and MERRA.

be seen as well. The CPC does not show such trends in those regions. To investigate the potential reasons and explanations for such behavior, a detailed investigation in the seasonal scale is conducted, the results of which are presented in section $5 \mathrm{~b}$.
As discussed in section $3 \mathrm{~b}$, the GP distribution is fitted to the AEDP sequences. The estimated scale parameters for MERRA, as shown in Fig. 9 (left), depict similar patterns to the CPC; however, like AMDP, MERRA underestimates the CPC scale parameter. Significant discrepancies and underestimations are identified in the Gulf Coast regions and the western United States. As for the shape parameter, while the continental-scale patterns for MERRA and CPC are reasonably similar, large discrepancies in the eastern United States and the Gulf Coast states are identified. Similar to the block maxima approach, a goodness-of-fit test was performed using the KS test. The null hypothesis was defined as to whether or not the declustered AEDP data in the empirical and theoretical CDFs belong to the same distribution. Using the empirical CDF and the theoretical GP $\mathrm{CDF}$ in the KS test, we determined that the GP distribution is, indeed, a good fit to the AEDP data.

\section{Discussion}

As discussed in sections $4 \mathrm{a}$ and $4 \mathrm{~b}$, MERRA underestimates the location and scale parameters of the GEV and GP distributions. The result of this is that MERRA produces lower-magnitude extreme precipitation events when compared to the CPC dataset. One point worth mentioning here is that, although the CPC is derived from ground-based observation data, the quality of its estimates depends highly on station density and station distribution within each grid box. The interpolation methods that are used for producing gridded datasets from point and sparse gauge measurements can introduce a considerable level of uncertainty into the gridded dataset, particularly in the mountainous and remote regions, where a sufficient number of rain gauge stations are usually not available. Hence, observational and interpolation uncertainties in the CPC gridded dataset also contribute to the observed differences between CPC and MERRA.

The two major trend discrepancies that were identified in MERRA will be discussed in detail in the next two subsections.

\section{a. Negative trend in MERRA over Nebraska-Kansas}

A feature that has been repeatedly identified in MERRA (Figs. 3, 5, 8) is a negative trend over Nebraska and Kansas, which is the opposite of what observations show. We looked at the time series of annual maximum daily precipitation for MERRA and CPC over this region and the respective GEV trends there. As shown in Fig. 10 (top), while CPC shows an increasing trend $\left(+0.17 \pm 0.097 \mathrm{~mm} \mathrm{day}^{-1} \mathrm{yr}^{-1}\right)$, MERRA shows a decreasing trend $\left(-0.26 \pm 0.073 \mathrm{~mm} \mathrm{day}^{-1} \mathrm{yr}^{-1}\right)$. To test 

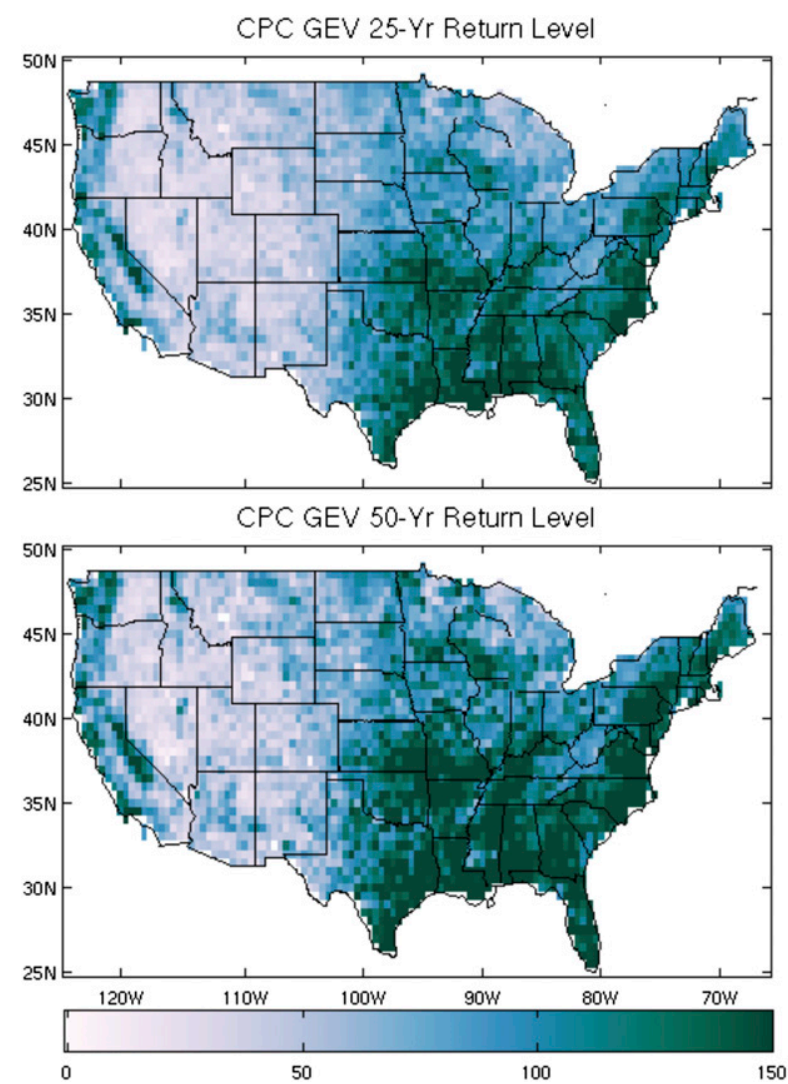
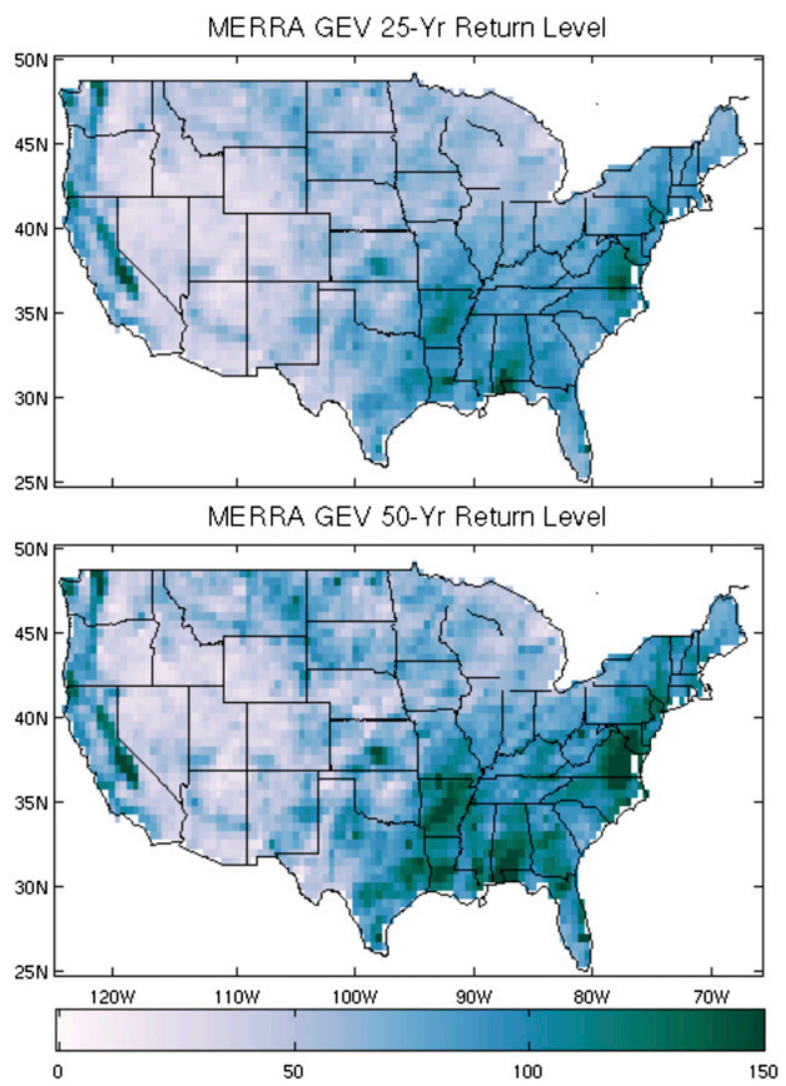

FIG. 7. The (top) 25- and (bottom) 50-yr return levels from time-variant GEV distributions for (left) CPC and (right) MERRA.

whether or not the estimated trends are different from zero, the respective $z$ scores are calculated and tested at the 5\% significance level. The resulting $z$ scores for the CPC trend $(+1.69)$ and the MERRA trend $(-3.58)$ indicate that the negative trend in MERRA's GEV trend is, indeed, statistically significant at the 5\% significance level.

There are a number of factors in the construction process of MERRA that can contribute to such spurious trends and to not correctly replicating the observations. Among them are boundary layer parameterization, land-atmosphere interactions, and/or convective precipitation parameterization. Robertson et al. (2011) studied the effects of the two observing system epoch changes: the Advanced Microwave Sounding Unit-A (AMSU-A) series in late 1998 and the Special Sensor Microwave Imager (SSM/I) in late 1987. The results show that precipitation is very sensitive to the changing observing system. In addition, Bosilovich (2013) found that the range of seasonal precipitation over the central United States decreases relative to the observation, identifying that to be related to a deficiency in the model land-atmosphere interactions. In addition, a negative correlation between the analysis increment and precipitation in the annual mean time series was identified in this region; however, it is not yet completely understood if such a correlation is causal or not. In another study, Trenberth et al. (2011) showed that the mean atmosphere moisture divergence (expressed as evaporation minus precipitation) extracted from MERRA data in this region (over land) is positive, which is unrealistic. This triggered a study by Bosilovich et al. (2015), where the observational influences on regional water budgets in different reanalyses were evaluated. The study shows that there has been an effect of the changing observations on the central U.S. water cycle. A satellite instrument on the Advanced Television and Infrared Observation Satellite (TIROS) Operational Vertical Sounder (ATOVS) changed the water vapor analysis at 0600 and 1800 UTC when no radiosondes are available to anchor the analysis. This has apparently affected the water vapor analysis and, consequently, the local water cycle in the central United States, more so than in other regions. It is, however, noteworthy that some of the interannual variability seems well represented in MERRA, as shown in Fig. 10 (bottom). Obvious structural discontinuities in precipitation mean do not appear in the CPC and MERRA AMDP series during 1979-2010. 

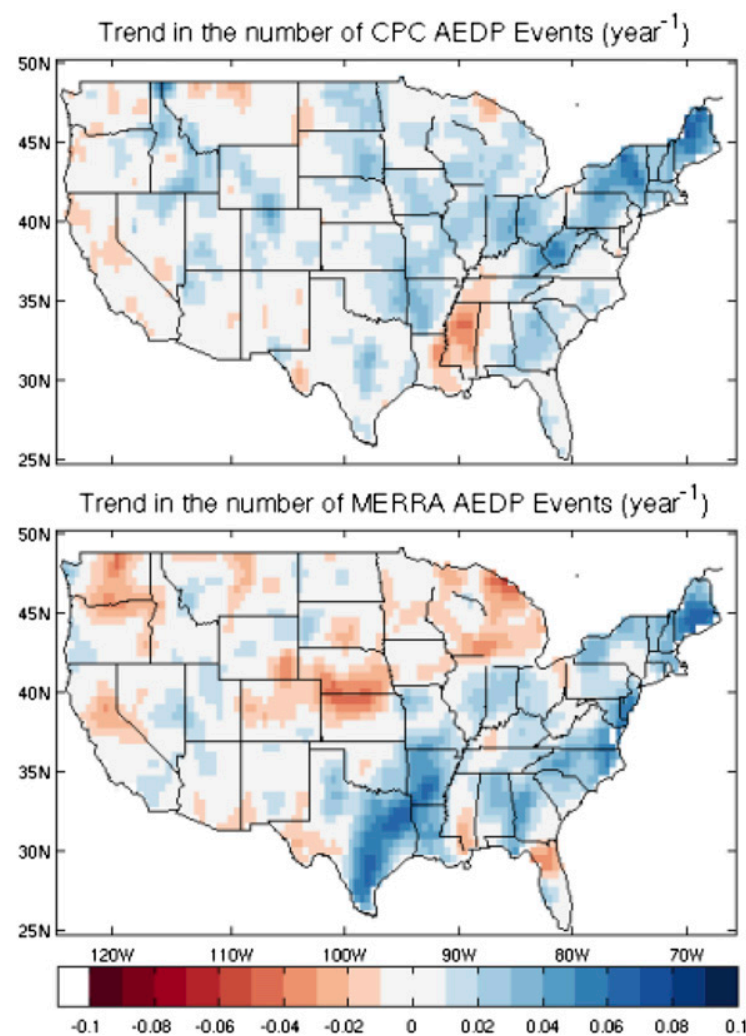

Significant trend $(95 \% \mathrm{Cl})$ in the number of CPC AEDP Events (year ${ }^{-1}$ )

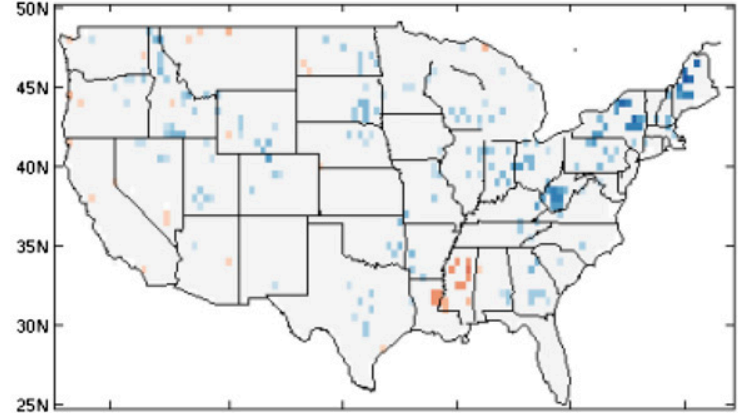

Significant trend $(95 \% \mathrm{CI})$ in the number of MERRA AEDP Events $\left(\right.$ year $\left.^{-1}\right)$

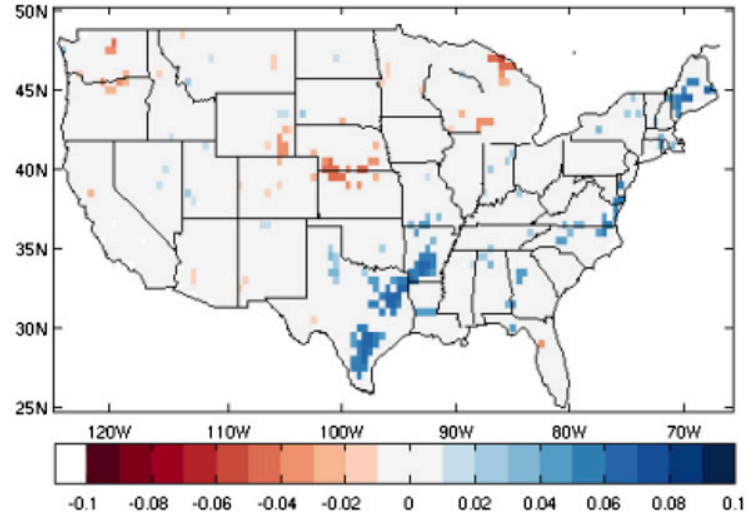

FIG. 8. (left) Trend in the number of AEDP events $\left(\mathrm{yr}^{-1}\right)$ in the (top) CPC and (bottom) MERRA. (right) The regions where the trend is statistically significant at a $5 \%$ significance level.

In addition to the above explanations, an alternative explanation or contributing factor could be the changes in the available stations used to create the CPC dataset. In this regard, we calculated the average number of stations over the Kansas-Nebraska region. We found that there is a jump around 1991-92 and a drop around 2004 in the number of stations used in CPC. This is consistent with the results reported in Chen et al. (2008b). However, looking at the time series analysis presented in Figs. 10 and 12 (Fig. 12 is described in greater detail below), the precipitation and anomalies do not seem to significantly change at the times of the above changes in the number of stations. It is also noteworthy that scaling issue (Zolina et al. 2014; Wehner et al. 2014) could be another contributing factor as well. The upscaling preprocessing that was initially performed on both datasets to bring them all into the $0.5^{\circ}$ would decrease this effect.

\section{b. Gulf Coast and East Coast positive trends}

By observing Figs. 3, 5, and 8, it seems there are possibilities for biases in the maximum daily precipitation over the Gulf Coast and East Coast regions toward the tropical cyclones in these regions (Rauber et al. 2008) that hit the southeastern and eastern areas of the United States. This raises the possibility of an existing bias in the MERRA model land-atmosphere interactions toward these cyclones.

To further investigate this issue, we studied the seasonality of the extreme precipitation events. In addition to DJF, March-May (MAM), JJA, and SeptemberNovember (SON) seasons, because the MERRA positive trend tracks displayed in Fig. 9 show high correlation with the Gulf Coast and East Coast cyclones, we also looked at the hurricane season (HUR). Based on the definition of the National Hurricane Center (NHC), the HUR starts from the beginning of June and ends at the end of November. The time series of seasonal maximum daily rainfall for each of the above five seasons were constructed, and statistically significant trends in seasonal maxima were investigated. Figure 11 shows the significant trends $\left(\mathrm{mm} \mathrm{day}^{-1} \mathrm{yr}^{-1}\right)$ at the $5 \% \mathrm{sig}$ nificance level in seasonal (DJF, MAM, JJA, SON, and HUR) maximum daily precipitation in CPC and MERRA during 1979-2010. As shown, both datasets generally show increasing trends in seasonal extreme rainfall in all of the seasons in the eastern part of the country; the largest increasing trends occur in $\mathrm{SON}$, as well as during the HUR season.

Discrepancies between the CPC and MERRA precipitation trends over the Gulf Coast region are clear 

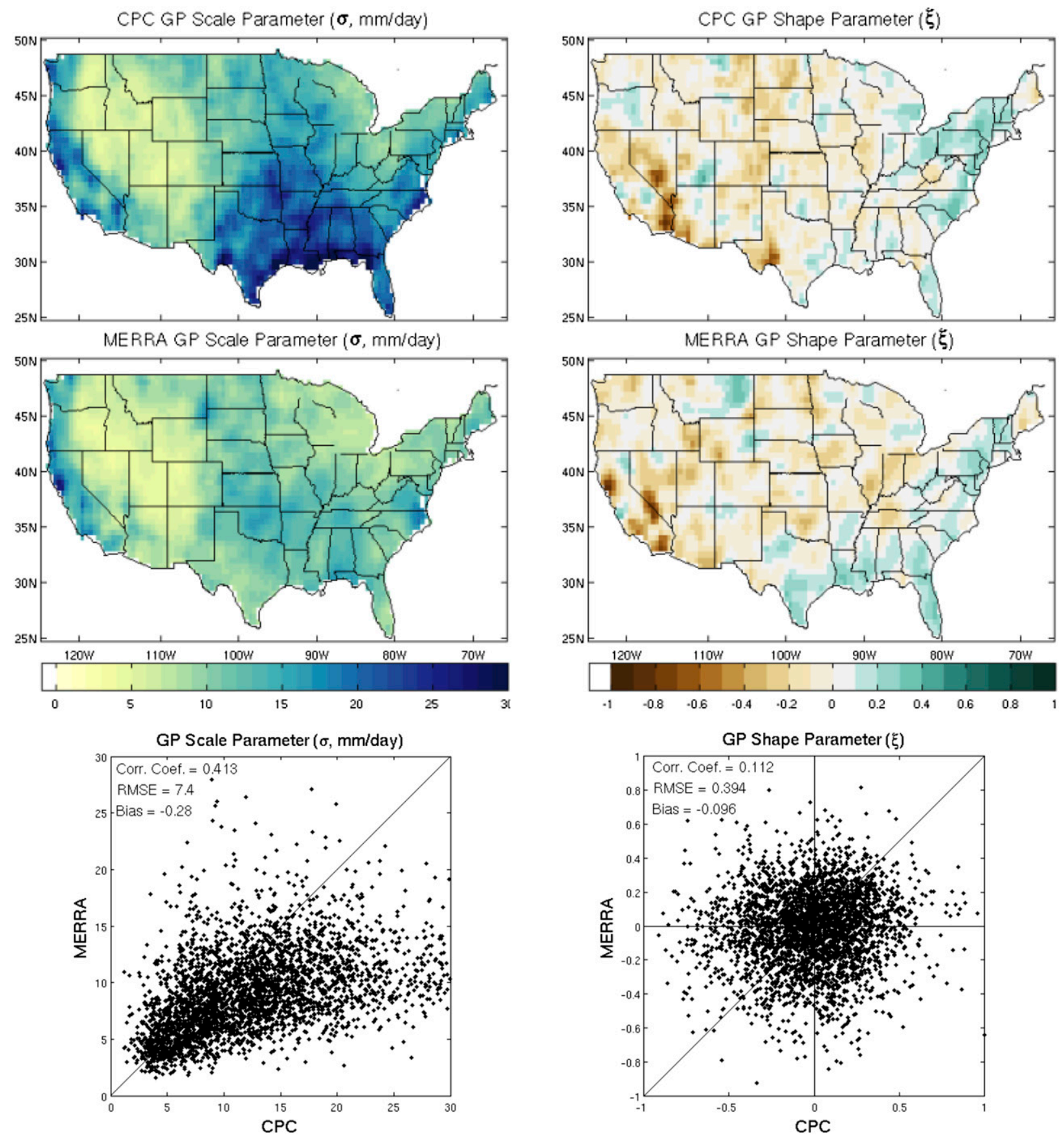

FIG. 9. Estimated (left) scale and (right) shape parameters of the GP distribution of AEDP for (top) CPC and (middle) MERRA during 1979-2010. (bottom) The respective scatterplots and quantitative statistics between the GP parameters from the CPC and MERRA.

in the DJF (Fig. 11) season where, unlike the CPC, MERRA shows a statistically significant positive trend over this region. For further investigation, we looked at the time series of each season's maximum precipitation and respective GEV trend over the southeastern United States (covering $30^{\circ}-38^{\circ} \mathrm{N}, 85^{\circ}-95^{\circ} \mathrm{W}$ ). The results are presented in Fig. 12. As shown, MERRA replicates the trends in the MAM, JJA, SON, and HUR seasons relatively well. Moreover, looking at the seasonal precipitation anomalies in Fig. 12 (left), MERRA shows good performance in mirroring the interannual precipitation anomalies similar to observation, particularly for more recent years after 1999, where the AMSU-A data were added into the observational dataset. 


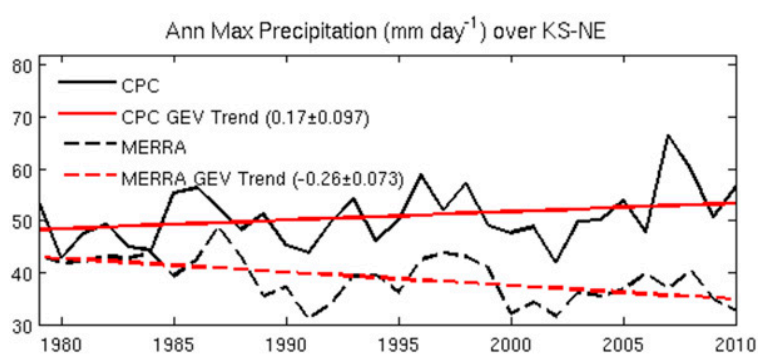

Ann Max Precipitation Anomaly (mm day ${ }^{-1}$ ) over KS-NE

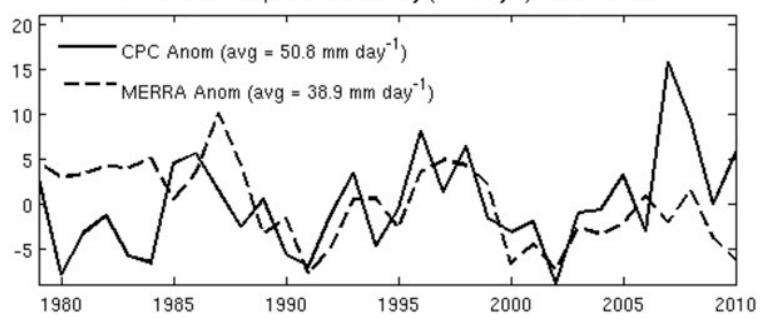

FIG. 10. (top) Time series and GEV trends in AMDP over Kansas and Nebraska, along with (bottom) the respective anomalies for CPC (solid line) and MERRA (dashed line) during 19792010.

For the DJF season, the spurious positive trend in MERRA is identified. This increasing trend in DJF helps to reinforce the increasing annual trend in the MERRA AMDP; however, in the CPC, the decreasing trend in DJF works against the SON, making the annual trend in the CPC AMDP weaker. For the years where only a few tropical cyclones occurred over the Gulf Coast region, the DJF trends contribute a much stronger signal to the annual trend, especially in weak spots in MERRA.

Also worth mentioning is that, in the southwestern United States, a significant decreasing trend in extreme rainfall was identified in the MAM and JJA seasons. These results are consistent with the trend results in seasonal maximum 5-day precipitation totals presented by Alexander et al. (2006).

With respect to the spurious negative trend in the central United States in MERRA, as shown in Fig. 11, the MAM season is the main season in which a major portion of this trend occurs. The HUR, JJA, and SON seasons also partly show the negative trend in this region.

\section{Conclusions}

In summary, we evaluated the performance of MERRA in capturing the trend and reproducing the distribution of historical precipitation extremes over the CONUS during 1979-2010. We started with the analysis of the climatology, number of wet days, and intensity (scaled to the number of wet days) of annual and seasonal precipitation extremes. The results show that MERRA reasonably mirrors the continental-scale patterns of change as observed by CPC while underestimating the magnitude of extremes, particularly over the Gulf Coast regions. MERRA overestimates the frequency at which the 99th percentile is exceeded. The value representing the 99th percentile of precipitation in MERRA is lower compared to CPC and is apparent in the underestimation in the intensity of precipitation on days that exceeded the 99th percentile. This feature is dominant in the JJA (summer) season and is observed to a lesser extent in the other seasons. Using the extreme value theory (EVT), we modeled two categories of extremes using two approaches: 1) block maxima and 2) peaks over threshold. The resulting categories are termed annual maximum daily precipitation (AMDP) and annual extreme daily precipitation (AEDP; representing the top $1 \%$ heavy rainfall events), respectively. For comparison purposes, the CPC U.S. Unified gridded precipitation data product was used as the gridded observation dataset. Based on the observations, the eastern and, in particular, the northeastern parts of the United States are experiencing positive trends in the AMDP intensity. In the western parts of the country, a mix of both negative and positive trends is identified. In addition, looking at the trend in the number of AEDP events over time, we find that the northern, northeastern, and central United States have experienced increasing trends from 1979 to 2010. This trend is negative for the western, southwestern, and northwestern United States.

The results showed that, in general, MERRA can reasonably mirror the continental patterns of changes and trends as seen in the observational data. This result was not expected before, particularly given the level of difficulty in constraining the rainfall in reanalyses products.

We built time-invariant GEV and GP models to investigate how well MERRA can reproduce the distribution of extreme precipitation events. Moreover, in order to account for the possible effects of climate change, a time-variant GEV model was also constructed, in which its location parameter was relaxed to change over time. The results show that MERRA tends to underestimate the location and scale parameters of the GEV distributions, particularly over the Gulf Coast states, as well as along the East and West Coasts. Similar behaviors are identified in the case of POT modeling using GP distribution.

We found two issues with MERRA's precipitation product. One is a spurious negative trend in the central United States, mainly over Nebraska and Kansas. We discuss that such spurious trends have most likely originated from a change in the observing system over time in and around the central United States, which has apparently affected the local water cycle in this region. In 
Significant trend $(95 \% \mathrm{Cl})$ in CPC DJF Maxima ( $\mathrm{mm} \mathrm{day}^{-1}$ year $^{-1}$ )

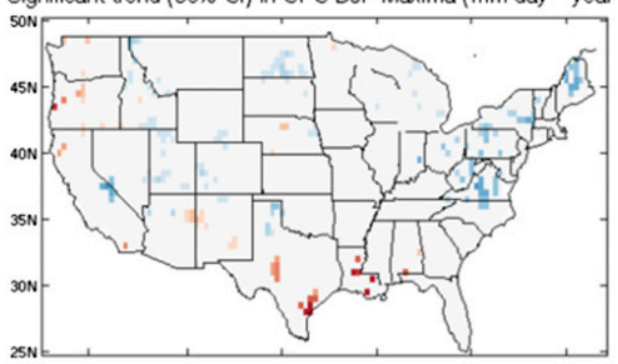

Significant trend $(95 \% \mathrm{CI})$ in CPC MAM Maxima $\left(\mathrm{mm}\right.$ day $^{-1}$ year $\left.^{-1}\right)$

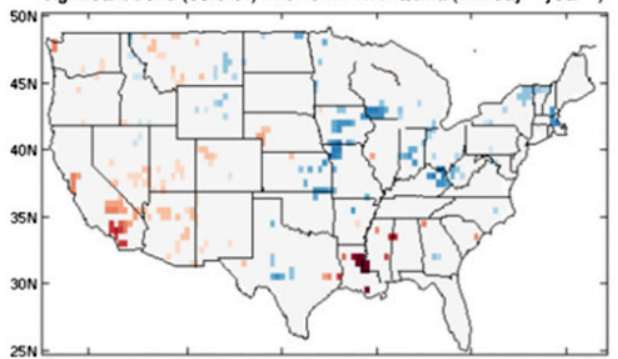

Significant trend $(95 \% \mathrm{CI})$ in CPC JJA Maxima $\left(\mathrm{mm}\right.$ day $^{-1}$ year $\left.^{-1}\right)$

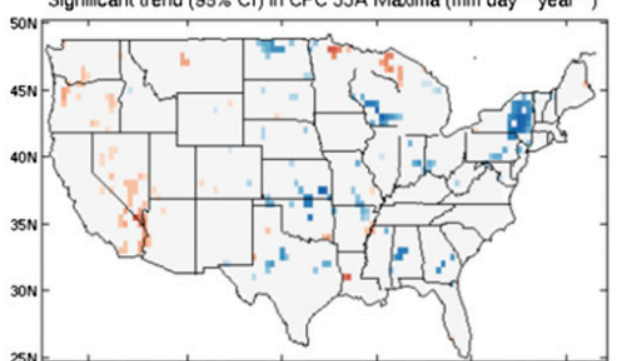

Significant trend $(95 \% \mathrm{CI})$ in CPC SON Maxima $\left(\mathrm{mm}\right.$ day ${ }^{-1}$ year $\left.^{-1}\right)$

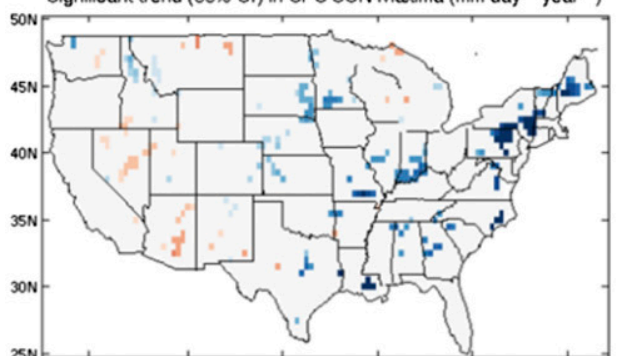

Significant trend $(95 \% \mathrm{CI})$ in CPC HUR Maxima (mm day ${ }^{-1}$ year $^{-1}$ )

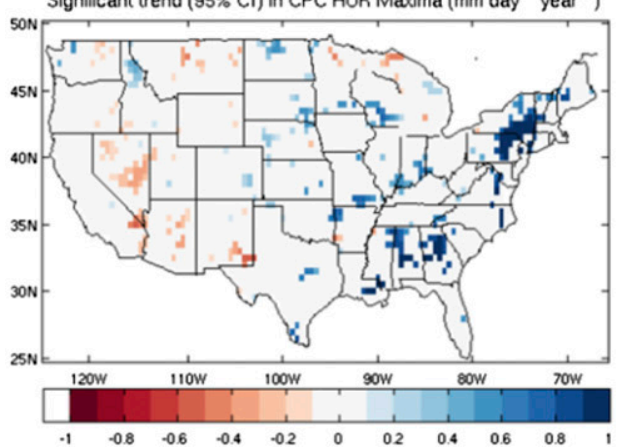

Significant trend $(95 \% \mathrm{Cl})$ in MERRA DJF Maxima $\left(\mathrm{mm} \mathrm{day}^{-1}\right.$ year $^{-1}$ )

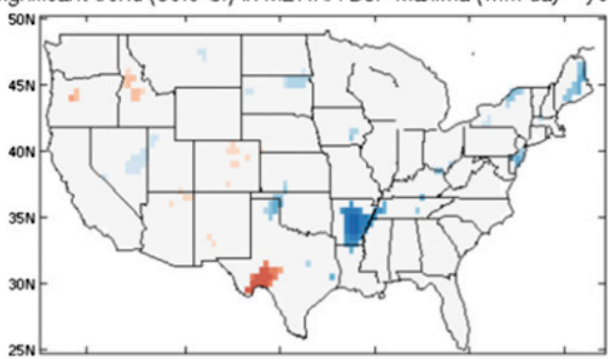

Significant trend $(95 \% \mathrm{CI})$ in MERRA MAM Maxima $\left(\mathrm{mm}\right.$ day $^{-1}$ year $\left.^{-1}\right)$

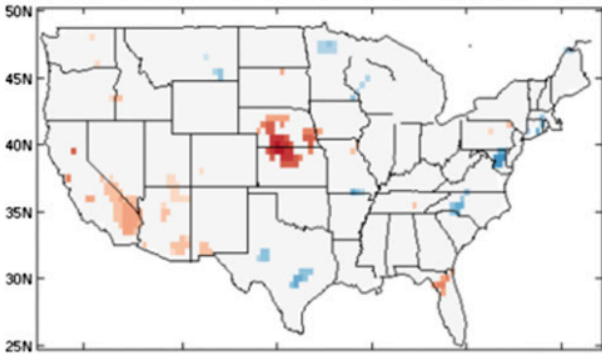

Significant trend $(95 \% \mathrm{Cl})$ in MERRA JJA Maxima $\left(\mathrm{mm} \mathrm{day}^{-1}\right.$ year $\left.^{-1}\right)$

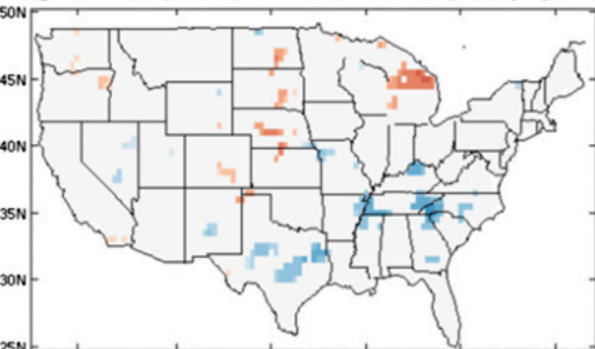

Significant trend $(95 \% \mathrm{CI})$ in MERRA SON Maxima $\left(\mathrm{mm} \mathrm{day}^{-1}\right.$ year $^{-1}$ )

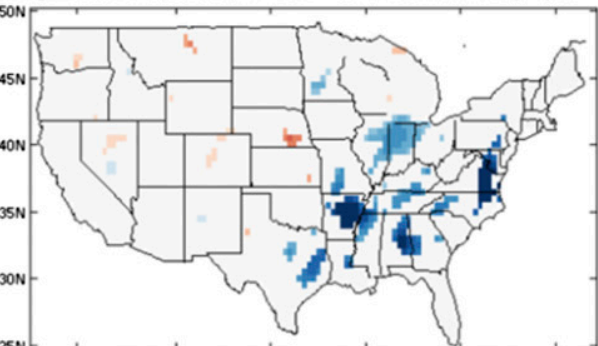

Significant trend $(95 \% \mathrm{Cl})$ in MERRA HUR Maxima ( $\mathrm{mm} \mathrm{day}^{-1}$ year ${ }^{-1}$ )

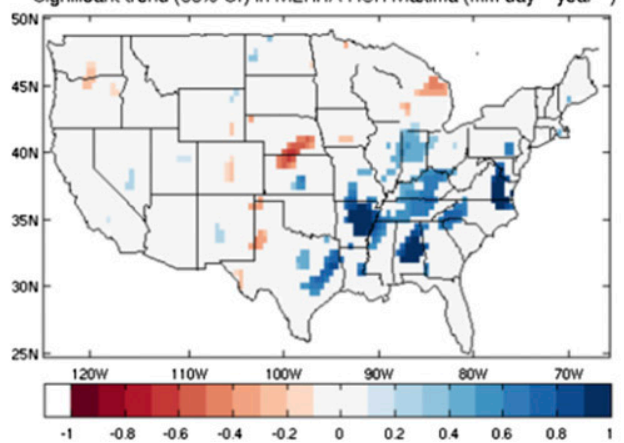

FIG. 11. Statistically significant trends $\left(\mathrm{mm} \mathrm{day}^{-1} \mathrm{yr}^{-1}\right)$ in seasonal (from top to bottom: DJF, MAM, JJA, SON, and HUR) max daily precipitation for (left) CPC and (right) MERRA during 1979-2010. 
DJF Max Precipitation ( $\mathrm{mm}$ day $^{-1}$ ) over SE

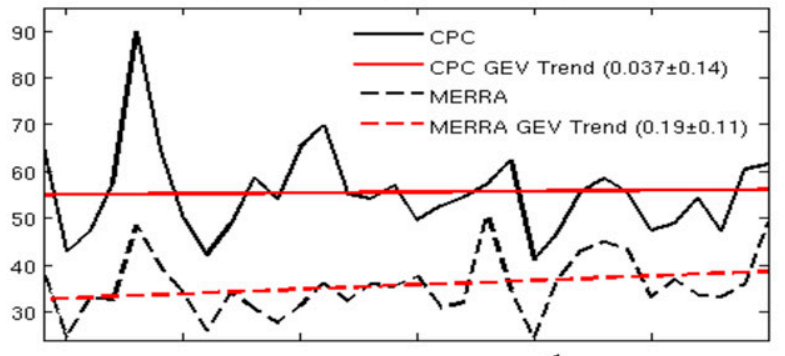

MAM Max Precipitation ( $\mathrm{mm}$ day $^{-1}$ ) over SE

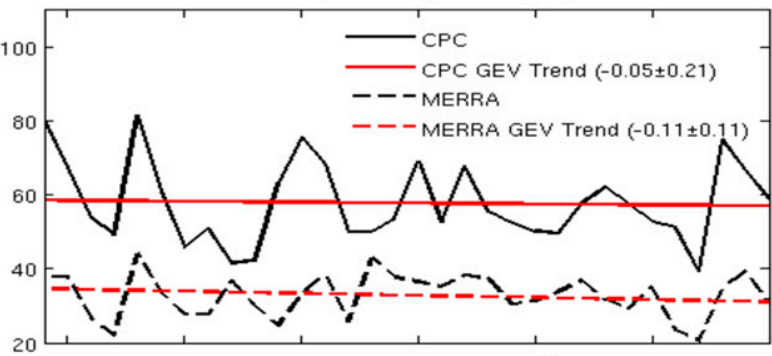

JJA Max Precipitation ( $\mathrm{mm}$ day $^{-1}$ ) over SE

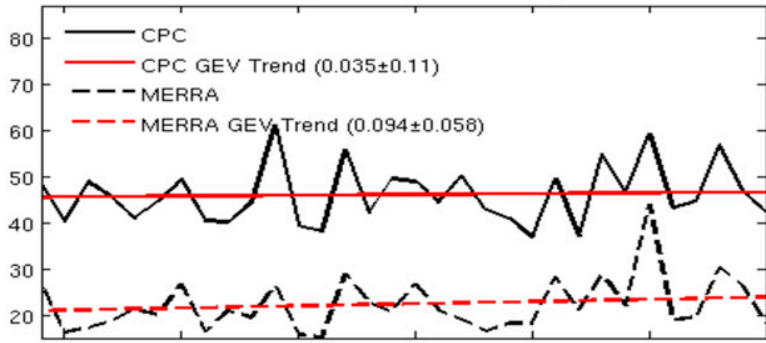

SON Max Precipitation ( $\mathrm{mm}$ day $^{-1}$ ) over SE

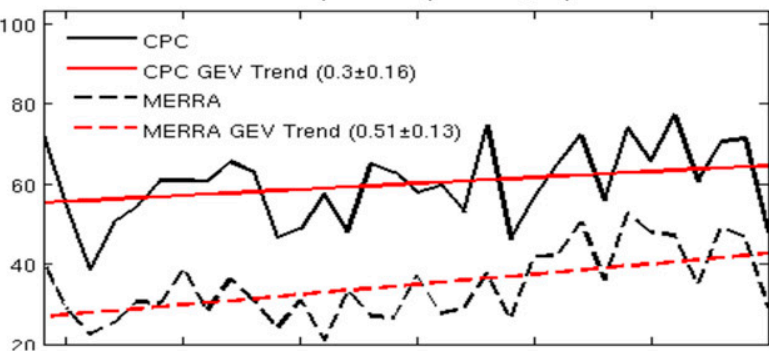

HUR Max Precipitation ( $\mathrm{mm} \mathrm{day}^{-1}$ ) over SE

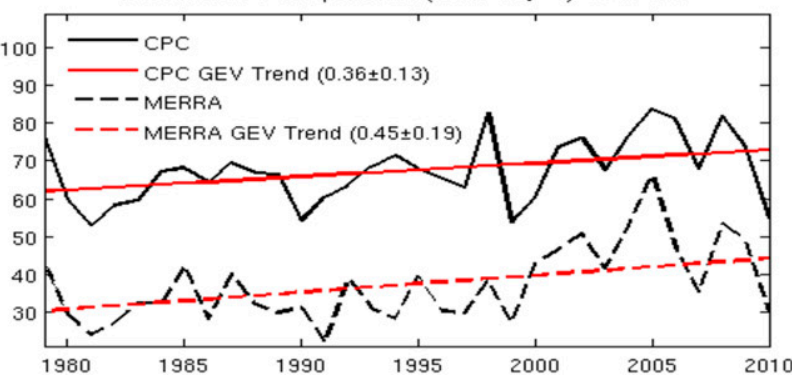

DJF Max Precipitation Anomaly ( $\mathrm{mm}$ day $^{-1}$ ) over SE

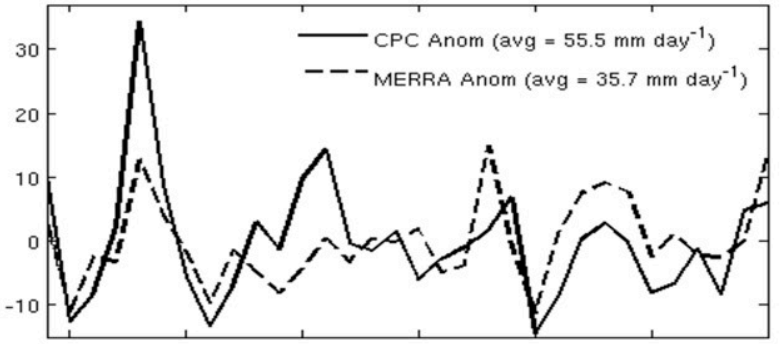

MAM Max Precipitation Anomaly $\left(\mathrm{mm} \mathrm{day}^{-1}\right)$ over SE

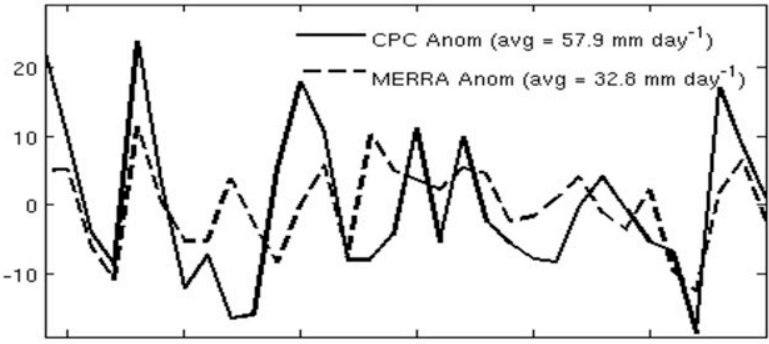

JJA Max Precipitation Anomaly ( $\mathrm{mm}$ day $^{-1}$ ) over SE

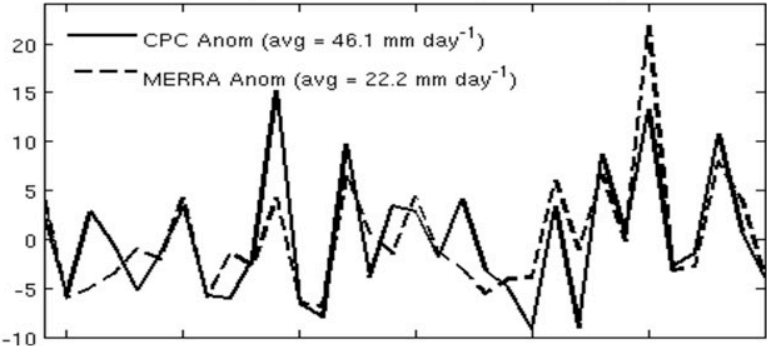

SON Max Precipitation Anomaly $\left(\mathrm{mm} \mathrm{day}^{-1}\right)$ over SE

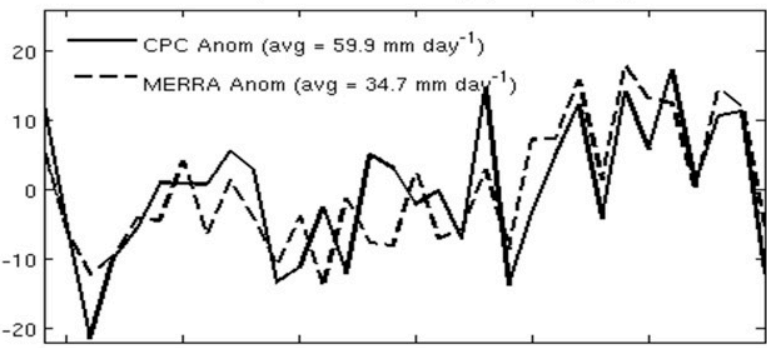

HUR Max Precipitation Anomaly ( $\mathrm{mm} \mathrm{day}^{-1}$ ) over SE

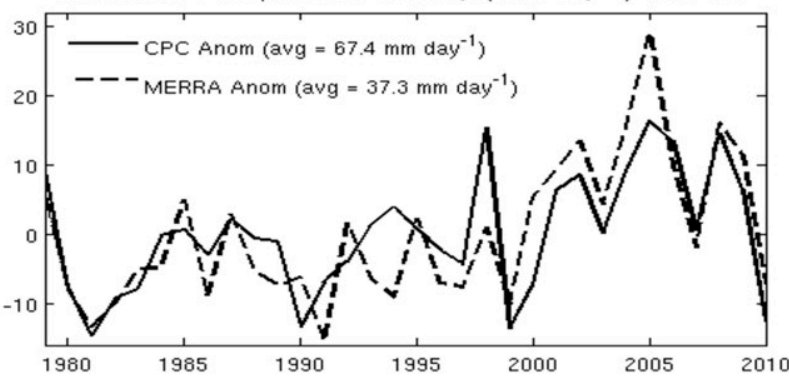

FIG. 12. (left) Time series and GEV trends in seasonal (from top to bottom: DJF, MAM, JJA, SON, and HUR) max daily precipitation over the Southeast, along with (right) the respective anomalies for CPC (solid line) and MERRA (dashed line) during 1979-2010. 
addition, the changes in the number of stations used in constructing CPC gridded data could be another contributing factor as well. In addition, a decrease in the range of seasonal precipitation over the central United States has been identified, most likely related to limitations in land-atmosphere interactions (Bosilovich 2013).

The second issue is related to the positive trend patterns over the Gulf Coast states and along the East Coast. The trend patterns in these regions seem correlated with the tracks that the Gulf Coast and East Coast cyclones usually take when making landfall over the CONUS. To further look into this issue, we investigated the potential trends in the seasonal maximum daily precipitation events. The results show that the SON and HUR seasons are the ones that are contributing to a major portion of the positive trend in this region. Moreover, an increasing trend in DJF over this region, unlike what the CPC data show, enhances the annual positive trend signal. This can be particularly important in years where few tropical cyclones make landfall. A detailed investigation into GEOS-5 and the assimilation techniques used in the MERRA product is required to enable the community to make more detailed inferences about the reasons for such patterns.

In addition to the above results, this study also shows that the family of the GEV distributions are, indeed, the right distributions for modeling the behavior of extreme precipitation events.

An important point to take into account, while interpreting the results, is that CPC is derived from point ground-based measurements. Rain gauge stations can be very dense in some regions, while too sparse in some other regions. Utilization of interpolation techniques to create gridded products, on the one hand, and the sparseness of the gauge measurements, on the other hand, can and do introduce uncertainties into the final gridded product. Thus, when we attempt to evaluate the performance of the MERRA and the observed discrepancies against the CPC gridded dataset, we need to consider the fact that the CPC estimates can be also far from perfect. Therefore, in short, the reported discrepancies in this study can originate both from inadequacies in the observations and in the reanalysis product. Hence, our focus on this work has been mainly on large-scale patterns.

The next step is to expand our study to include other reanalyses, such as the ERA-Interim and the NCEP Climate Forecast System Reanalysis (CFSR), as well as a newly developed, satellite-based, long-term precipitation dataset called Precipitation Estimation from Remotely Sensed Information Using Artificial Neural Networks Climate Data Record (PERSIANN-CDR; Ashouri et al. 2015; Miao et al. 2015), which provides rainfall estimates over the period $1983-2014$ (present) at $0.25^{\circ}$ and daily frequencies.
Acknowledgments. The CPC U.S. Unified precipitation data are provided by the NOAA/OAR/ESRL PSD, Boulder, Colorado, from their website (http://www.esrl. noaa.gov/psd/). The MERRA product is accessible through the Goddard Earth Sciences Data Information Services Center (GES DISC; http://disc.sci.gsfc.nasa.gov/ mdisc/overview). The authors would like to thank the anonymous reviewers for the constructive comments. In addition, the authors would like to thank Dr. Jin-Yi Yu, professor at the Department of Earth System Science at the University of California, Irvine, for his insightful comments on the tropical cyclones. We would also like to thank Dr. Tsou Chun Jaw at the Center for Hydrometeorology and Remote Sensing for his assistance in data processing. Ashouri was supported by the NASA Earth and Space Science Fellowship (NESSF; Award NNX12AO11H). Hsu and Sorooshian were supported by the NOAA Climate Change Data and Detection (CCDD; Grant NA10DAR4310122), the NASA Decision Support System (Grant NNX09A067G), and the Army Research Office (Grant W911NF-11-1-0422). Lee was partially supported by the NSF (Grant DMS 1107225), and Wehner was supported by the Regional and Global Climate Modeling Program of the Office of Biological and Environmental Research in the Department of Energy Office of Science under Contract DE-AC0205CH11231 (LBNL).

\section{REFERENCES}

Alexander, L. V., and Coauthors, 2006: Global observed changes in daily climate extremes of temperature and precipitation. J. Geophys. Res., 111, D05109, doi:10.1029/2005JD006290.

Ashouri, H., K.-L. Hsu, S. Sorooshian, D. K. Brathwaite, K. R. Knapp, L. D. Cecil, B. R. Nelson, and O. P. Prat, 2015: PERSIANN-CDR: Daily precipitation climate data record from multisatellite observations for hydrological and climate studies. Bull. Amer. Meteor. Soc., 96, 69-83, doi:10.1175/ BAMS-D-13-00068.1.

Bloom, S., L. Takacs, A. DaSilva, and D. Ledvina, 1996: Data assimilation using incremental analysis updates. Mon. Wea. Rev., 124, 1256-1271, doi:10.1175/1520-0493(1996)124<1256: DAUIAU $>2.0 . \mathrm{CO} ; 2$.

Bosilovich, M. G., 2013: Regional climate and variability of NASA MERRA and recent reanalyses: U.S. summertime precipitation and temperature. J. Appl. Meteor. Climatol., 52, 1939-1951, doi:10.1175/JAMC-D-12-0291.1.

_ J. Chen, F. R. Robertson, and R. F. Adler, 2008: Evaluation of global precipitation in reanalyses. J. Appl. Meteor. Climatol., 47, 2279-2299, doi:10.1175/2008JAMC1921.1.

_ F. R. Robertson, and J. Chen, 2011: Global energy and water budgets in MERRA. J. Climate, 24, 5721-5739, doi:10.1175/ 2011JCLI4175.1.

- J. D. Chern, D. Mocko, F. R. Robertson, and A. M. da Silva, 2015: Evaluating observation influence on regional water budgets in reanalyses. J. Climate, 28, 3631-3649, doi:10.1175/ JCLI-D-14-00623.1. 
Brown, S. J., J. Caesar, and C. A. T. Ferro, 2008: Global changes in extreme daily temperature since 1950. J. Geophys. Res., 113, D05115, doi:10.1029/2006JD008091.

Castillo, E., A. S. Hadi, N. Balakrishnan, and J. M. Sarabia, 2005: Extreme Value and Related Models with Applications in Engineering and Science. John Wiley \& Sons, 362 pp.

Chen, M., W. Shi, P. Xie, V. B. S. Silva, V. E. Kousky, R. W. Higgins, and J. E. Janowiak, 2008a: Assessing objective techniques for gauge-based analyses of global daily precipitation. J. Geophys. Res., 113, D04110, doi:10.1029/2007JD009132.

, and Coauthors, 2008b: CPC Unified gauge-based analysis of global daily precipitation. Western Pacific Geophysics Meeting, Cairns, Australia, Amer. Geophys. Union. [Available online at ftp://ftp.cpc.ncep.noaa.gov/precip/CPC_UNI_PRCP/ GAUGE_CONUS/DOCU/Chen_et_al_2008_Daily_Gauge_ Anal.pdf.]

Coles, S. G., 2001: An Introduction to Statistical Modeling of Extreme Values. Springer, $225 \mathrm{pp}$.

Cooley, D., 2009: Extreme value analysis and the study of climate change: A commentary on Wigley 1988. Climatic Change, 97, 77-83, doi:10.1007/s10584-009-9627-x.

_ 2013: Return periods and return levels under climate change. Extremes in a Changing Climate: Detection, Analysis, and Uncertainty, A. AghaKouchak et al., Eds., Springer, 97-114.

__ and S. R. Sain, 2010: Spatial hierarchical modeling of precipitation extremes from a regional climate model. J. Agric. Biol. Environ. Stat., 15, 381-402, doi:10.1007/ s13253-010-0023-9.

DeGaetano, A. T., 2009: Time-dependent changes in extremeprecipitation return-period amounts in the continental United States. J. Appl. Meteor. Climatol., 48, 2086-2099, doi:10.1175/ 2009JAMC2179.1.

Dulière, V., Y. X. Zhang, and E. P. Salathé, 2013: Changes in twentieth-century extreme temperature and precipitation over the western United States based on observations and regional climate model simulations. J. Climate, 26, 8556-8575, doi:10.1175/JCLI-D-12-00818.1.

Easterling, D. R., J. L. Evans, P. Ya. Groisman, T. R. Karl, K. E. Kunkel, and P. Ambenje, 2000: Observed variability and trends in extreme climate events: A brief review. Bull. Amer. Meteor. Soc., 81, 417-425, doi:10.1175/1520-0477(2000)081<0417: OVATIE $>2.3 . \mathrm{CO} ; 2$.

Fisher, R. A., and L. H. C. Tippett, 1928: Limiting forms of the frequency distribution of the largest or smallest member of a sample. Proc. Cambridge Philos. Soc., 24, 180-190, doi:10.1017/ S0305004100015681.

Gervais, M., J. Gyakum, E. Atallah, L.-B. Tremblay, and R. B. Neale, 2014: How well are the distribution and extreme values of daily precipitation over North America represented in the Community Climate System Model? A comparison to reanalysis, satellite, and gridded station data. J. Climate, 27, 5219-5239, doi:10.1175/JCLI-D-13-00320.1.

Groisman, P. Ya., R. W. Knight, D. R. Easterling, T. R. Karl, G. C. Hegerl, and V. A. N. Razuvaev, 2005: Trends in intense precipitation in the climate record. J. Climate, 18, 1326-1350, doi:10.1175/JCLI3339.1.

,-- , and T. R. Karl, 2012: Changes in intense precipitation over the central United States. J. Hydrometeor., 13, 47-66, doi:10.1175/JHM-D-11-039.1.

Higgins, R. W., J.-K. E. Schemm, W. Shi, and A. Leetmaa, 2000: Extreme precipitation events in the western United States related to tropical forcing. J. Climate, 13, 793-820, doi:10.1175/ 1520-0442(2000)013<0793:EPEITW>2.0.CO;2.
Horton, R., and Coauthors, 2014: Northeast. Climate Change Impacts in the United States: The Third National Climate Assessment, J. M. Melillo, T. C. Richmond, and G. W. Yohe, Eds., U.S. Global Change Research Program, 371-395. [Available online at http://nca2014.globalchange.gov/report.]

IPCC, 2013: Climate Change 2013: The Physical Science Basis. Cambridge University Press, 1535 pp. [Available online at http://www.climatechange2013.org/images/report/WG1AR5 ALL_FINAL.pdf.]

Karl, T. R., and Coauthors, 1993: A new perspective on recent global warming-Asymmetric trends of daily maximum and minimum temperature. Bull. Amer. Meteor. Soc., 74, 1007-1023, doi:10.1175/1520-0477(1993)074<1007:ANPORG>2.0.CO;2.

_ J. M. Melillo, and T. C. Peterson, Eds., 2009: Global Climate Change Impacts in the United States. Cambridge University Press, 188 pp.

— anomalies and trends. Eos, Trans. Amer. Geophys. Union, $\mathbf{9 3}$ 473-474, doi:10.1029/2012EO470001.

Katz, R. W., 2010: Statistics of extremes in climate change. Climatic Change, 100, 71-76, doi:10.1007/s10584-010-9834-5.

_ 2013: Statistical methods for nonstationary extremes. Extremes in a Changing Climate, A. AghaKouchak et al., Eds., Springer, 15-37.

- M. B. Parlange, and P. Naveau, 2002: Statistics of extremes in hydrology. Adv. Water Resour., 25, 1287-1304, doi:10.1016/ S0309-1708(02)00056-8

Kharin, V. V., F. W. Zwiers, X. Zhang, and G. C. Hegerl, 2007: Changes in temperature and precipitation extremes in the IPCC ensemble of global coupled model simulations. J. Climate, 20, 1419-1444, doi:10.1175/JCLI4066.1.

$-, \ldots,-$, and M. Wehner, 2013: Changes in temperature and precipitation extremes in the CMIP5 ensemble. Climatic Change, 119, 345-357, doi:10.1007/s10584-013-0705-8.

Kunkel, K. E., D. R. Easterling, D. A. R. Kristovich, B. Gleason, L. Stoecker, and R. Smith, 2010: Recent increases in U.S. heavy precipitation associated with tropical cyclones. Geophys. Res. Lett., 37, L24706, doi:10.1029/2010GL045164.

_- and Coauthors, 2013: Monitoring and understanding changes in extreme storm statistics: State of knowledge. Bull. Amer. Meteor. Soc., 94, 499-514, doi:10.1175/BAMS-D-11-00262.1.

Lee, J., S. Li, and R. Lund, 2014: Trends in extreme United States temperatures. J. Climate, 27, 4209-4225, doi:10.1175/ JCLI-D-13-00283.1.

Lucchesi, R., 2012: File specification for MERRA products GMAO Office Note 1 (version 2.3), 82 pp. [Available online at http://gmao.gsfc.nasa.gov/pubs/docs/Lucchesi528.pdf.]

Ma, L., T. Zhang, O. W. Frauenfeld, B. Ye, D. Yang, and D. Qin, 2009: Evaluation of precipitation from the ERA-40, NCEP-1, and NCEP-2 reanalyses and CMAP-1, CMAP-2, and GPCP-2 with ground-based measurements in China. J. Geophys. Res., 114, D09105, doi:10.1029/2008JD011178.

Massey, F. J., 1951: The Kolmogorov-Smirnov test for goodness of fit. J. Amer. Stat. Assoc., 46, 68-78, doi:10.1080/ 01621459.1951.10500769.

MathWorks, 2011: MATLAB release 2011b. Accessed 4 January 2016. [Available online at http://www.mathworks.com/products/ new_products/release2011b.html?s_tid=gn_loc_drop.]

Miao, C., H. Ashouri, K.-L. Hsu, S. Sorooshian, and Q. Duan, 2015: Evaluation of the PERSIANN-CDR daily rainfall estimates in capturing the behavior of extreme precipitation events over China. J. Hydrometeor., 16, 1387-1396, doi:10.1175/ JHM-D-14-0174.1. 
NCDC, 2012: Billion-dollar weather/climate events. Accessed 4 January 2016. [Available online at http://www.ncdc.noaa.gov/ billions.]

Peterson, T. C., and Coauthors, 2013: Monitoring and understanding changes in heat waves, cold waves, floods, and droughts in the United States: State of knowledge. Bull. Amer. Meteor. Soc., 94, 821-834, doi:10.1175/BAMS-D-12-00066.1.

_, T. R. Karl, J. P. Kossin, K. E. Kunkel, J. H. Lawrimore, J. R. McMahon, R. S. Vose, and X. G. Yin, 2014: Changes in weather and climate extremes: State of knowledge relevant to air and water quality in the United States. J. Air Waste Manage. Assoc., 64, 184-197, doi:10.1080/10962247.2013.851044.

Rana, S., J. McGregor, and J. Renwick, 2015: Precipitation seasonality over the Indian subcontinent: An evaluation of gauge, reanalyses, and satellite retrievals. J. Hydrometeor., 16, 631651, doi:10.1175/JHM-D-14-0106.1.

Rauber, R. M., J. E. Walsh, and D. J. Charlevoix, 2008: Severe and Hazardous Weather: An Introduction to High-Impact Meteorology. 3rd ed. Kendall/Hunt Publishing Company, 642 pp.

R Core Team, 2013: R: A language and environment for statistical computing. R Foundation for Statistical Computing, accessed 4 January 2016. [Available online at http://www.R-project.org/.]

Rienecker, M. M., and Coauthors, 2008: The GEOS-5 Data Assimilation System-Documentation of versions 5.0.1, 5.1.0, and 5.2.0. NASA Tech. Rep. Series on Global Modeling and Data Assimilation, NASA/TM-2008-104606, Vol. 27, 92 pp. [Available online at http://gmao.gsfc.nasa.gov/pubs/docs/ GEOS5_104606-Vol27.pdf.]

_ - and Coauthors, 2011: MERRA: NASA's Modern-Era Retrospective Analysis for Research and Applications. J. Climate, 24, 3624-3648, doi:10.1175/JCLI-D-11-00015.1.

Robertson, F. R., M. G. Bosilovich, J. Chen, and T. L. Miller, 2011: The effect of satellite observing system changes on MERRA water and energy fluxes. J. Climate, 24, 5197-5217, doi:10.1175/ 2011JCLI4227.1.

Schenkel, B. A., and R. E. Hart, 2012: An examination of tropical cyclone position, intensity, and intensity life cycle within atmospheric reanalysis datasets. J. Climate, 25, 3453-3475, doi:10.1175/2011JCLI4208.1.

Schubert, S., H. Wang, and M. Suarez, 2011: Warm season subseasonal variability and climate extremes in the Northern Hemisphere: The role of stationary Rossby waves. J. Climate, 24, 4773-4792, doi:10.1175/JCLI-D-10-05035.1.

Smith, A. B., and R. W. Katz, 2013: US billion-dollar weather and climate disasters: Data sources, trends, accuracy and biases. Nat. Hazards, 67, 387-410, doi:10.1007/s11069-013-0566-5.

Smith, C. A., G. P. Compo, and D. K. Hooper, 2014: Web-Based Reanalysis Intercomparison Tools (WRIT) for analysis and comparison of reanalyses and other datasets. Bull. Amer. Meteor. Soc., 95, 1671-1678, doi:10.1175/BAMS-D-13-00192.1.

Towler, E., B. Rajagopalan, E. Gilleland, R. S. Summers, D. Yates, and R. W. Kats, 2010: Modeling hydrologic and water quality extremes in a changing climate: A statistical approach based on extreme value theory. Water Resour. Res., 46, W11504, doi:10.1029/2009WR008876.

Trenberth, K. E., J. T. Fasullo, and J. Mackaro, 2011: Atmospheric moisture transports from ocean to land and global energy flows in reanalyses. J. Climate, 24, 4907-4924, doi:10.1175/ 2011JCLI4171.1.

Villarini, G., J. A. Smith, A. A. Ntelekos, and U. Schwarz, 2011: Annual maximum and peaks-over-threshold analyses of daily rainfall accumulations for Austria. J. Geophys. Res., 116, D05103, doi:10.1029/2010JD015038.

Wang, H., S. Schubert, R. Koster, Y.-G. Ham, and M. Suarez, 2014: On the role of SST forcing in the 2011 and 2012 extreme U.S. heat and drought: A study in contrasts. J. Hydrometeor., 15, 1255-1273, doi:10.1175/JHM-D-13-069.1.

Wehner, M. F., 2005: Changes in daily precipitation and surface air temperature extremes in the IPCC AR4 models. U.S. CLIVAR Variations, Vol. 3, No. 3, U.S. Climate Variability and Predictability Program, Washington, DC, 5-9. [Available online at http://www.usclivar.org/sites/default/files/Variations-V3N3.pdf.] ,2013: Very extreme seasonal precipitation in the NARCCAP ensemble: Model performance and projections. Climate Dyn., 40, 59-80, doi:10.1007/s00382-012-1393-1.

_ , and Coauthors, 2014: The effect of horizontal resolution on simulation quality in the Community Atmospheric Model, CAM5.1. J. Adv. Modeling Earth Syst., 6, 980-997, doi:10.1002/2013MS000276.

Westra, S., L. V. Alexander, and F. W. Zwiers, 2013: Global increasing trends in annual maximum daily precipitation. J. Climate, 26, 3904-3918, doi:10.1175/JCLI-D-12-00502.1.

Wuebbles, D. J., and Coauthors, 2014a: CMIP5 climate model analyses: Climate extremes in the United States. Bull. Amer. Meteor. Soc., 95, 571-583, doi:10.1175/BAMS-D-12-00172.1.

, K. Kunkel, M. Wehner, and Z. Zobel, 2014b: Severe weather in United States under a changing climate. Eos, Trans. Amer. Geophys. Union, 95, 149-150, doi:10.1002/2014EO180001.

Xie, P., M. Chen, S. Yang, A. Yatagai, T. Hayasaka, Y. Fukushima, and C. Liu, 2007: A gauge-based analysis of daily precipitation over East Asia. J. Hydrometeor., 8, 607-626, doi:10.1175/ JHM583.1.

- — , and W. Shi, 2010: CPC unified gauge-based analysis of global daily precipitation. Preprints, 24th Conf. on Hydrology, Atlanta, GA, Amer. Meteor. Soc., 2.3A. [Available online at http://ams.confex.com/ams/90annual/techprogram/paper_163676. htm.]

Zhang, X., W. D. Hogg, and E. Mekis, 2001: Spatial and temporal characteristics of heavy precipitation events over Canada. J. Climate, 14, 1923-1936, doi:10.1175/ 1520-0442(2001)014<1923:SATCOH $>2.0 . \mathrm{CO} ; 2$.

Zolina, O., A. Kapala, C. Simmer, and S. Gulev, 2004: Analysis of extreme precipitation over Europe from different reanalyses: A comparative assessment. Global Planet. Change, 44, 129161, doi:10.1016/j.gloplacha.2004.06.009.

, C. Simmer, K. P. Belyaev, S. K. Gulev, and K. P. Koltermann, 2013: Changes in European wet and dry spells over the last decades. J. Climate, 26, 2022-2047, doi:10.1175/JCLI-D-11-00498.1.

_ — _ A. Kapala, P. Shabanov, P. Becker, H. Mächel, S. Gulev, and P. Groisman, 2014: Precipitation variability and extremes in central Europe: New view from STAMMEX results. Bull. Amer. Meteor. Soc., 95, 995-1002, doi:10.1175/ BAMS-D-12-00134.1. 